\title{
Review Article \\ Peptide Receptor Targeting in Cancer: The Somatostatin Paradigm
}

\section{Federica Barbieri, Adriana Bajetto, Alessandra Pattarozzi, Monica Gatti, Roberto Würth, Stefano Thellung, Alessandro Corsaro, Valentina Villa, Mario Nizzari, and Tullio Florio}

\author{
Section of Pharmacology, Department of Internal Medicine and Center of Excellence for Biomedical Research (CEBR), \\ University of Genova, Viale Benedetto XV, 216132 Genova, Italy
}

Correspondence should be addressed to Tullio Florio; tullio.florio@unige.it

Received 29 September 2012; Revised 10 December 2012; Accepted 28 December 2012

Academic Editor: Hubert Vaudry

Copyright ( $) 2013$ Federica Barbieri et al. This is an open access article distributed under the Creative Commons Attribution License, which permits unrestricted use, distribution, and reproduction in any medium, provided the original work is properly cited.

\begin{abstract}
Peptide receptors involved in pathophysiological processes represent promising therapeutic targets. Neuropeptide somatostatin (SST) is produced by specialized cells in a large number of human organs and tissues. SST primarily acts as inhibitor of endocrine and exocrine secretion via the activation of five G-protein-coupled receptors, named sst1-5, while in central nervous system, SST acts as a neurotransmitter/neuromodulator, regulating locomotory and cognitive functions. Critical points of SST/SST receptor biology, such as signaling pathways of individual receptor subtypes, homo- and heterodimerization, trafficking, and cross-talk with growth factor receptors, have been extensively studied, although functions associated with several pathological conditions, including cancer, are still not completely unraveled. Importantly, SST exerts antiproliferative and antiangiogenic effects on cancer cells in vitro, and on experimental tumors in vivo. Moreover, SST agonists are clinically effective as antitumor agents for pituitary adenomas and gastro-pancreatic neuroendocrine tumors. However, SST receptors being expressed by tumor cells of various tumor histotypes, their pharmacological use is potentially extendible to other cancer types, although to date no significant results have been obtained. In this paper the most recent findings on the expression and functional roles of SST and SST receptors in tumor cells are discussed.
\end{abstract}

\section{Somatostatin and Somatostatin Receptors: An Overview}

Somatostatin (SST) is a cyclic neuropeptide containing a disulfide bond linking the cysteine residues at positions 3 and $14\left(\mathrm{Cys}_{3}-\mathrm{Cys}_{14}\right)$. Native SST has two molecular forms, SST-28 and SST-14, consisting of 28 or 14 a.a., respectively, derived from proteolysis of a larger precursor molecule, pre-pro-SST. SST is ubiquitously expressed in humans, with high concentrations in brain, liver, lungs, pancreas, thyroid, gastrointestinal tract, and adrenal gland mainly acting as an inhibitor of exocrine and endocrine secretions on target organs. For example, SST suppresses GH, prolactin, and TSH production from pituitary gland, insulin, glucagon and exocrine secretions from pancreas, and several gastrointestinal peptides [1].
In the brain, SST acts as neuromodulator, with physiological effects on neuroendocrine, motor, and cognitive functions, and as neurotransmitter, exerting both stimulatory and inhibitory effects [2]. Moreover, the synthesis of many growth factors (insulin-like growth factor 1, IGF-1; epidermal growth factor, EGF; fibroblast growth factor, FGF; vascularendothelial growth factor, VEGF) is also inhibited by SST $[3,4]$.

SST exerts its biologic effects by binding to five specific high-affinity receptors (sst1-5) on the cell surface [1, 5], belonging to the seven transmembrane, $G$ protein-coupled receptor (GPCR) family. SST-14 and SST-28 bind all SST receptors with similar high affinity although SST-28 preferentially binds to sst5, while synthetic ligands display distinct SST-specific binding affinity (Table 1). SST receptors are encoded by different intronless genes (located on 
TABLE 1: Binding affinities of native SST and synthetic agonists for SST receptor subtypes.

\begin{tabular}{|c|c|c|c|c|c|c|}
\hline \multirow{2}{*}{ Ligands } & & \multicolumn{5}{|c|}{ Binding affinity $\left(\mathrm{IC}_{50} \mathrm{nM}\right)$} \\
\hline & & sst1 & sst2 & sst3 & sst4 & sst5 \\
\hline \multirow{4}{*}{ Endogenous } & SST-14 & $0.1-2.26$ & $0.2-1.3$ & $0.3-1.6$ & $0.3-1.8$ & $0.2-0.9$ \\
\hline & SST-28 & $0.1-2.2$ & $0.2-4.1$ & $0.3-6.1$ & $0.3-7.2$ & $0.05-0.4$ \\
\hline & CST-14 & 2.1 & 0.5 & 3.8 & 18.2 & 0.9 \\
\hline & CST-17 & $0.25-7.0$ & $0.6-0.9$ & $0.4-0.6$ & $0.5-0.6$ & $0.3-0.4$ \\
\hline \multirow{3}{*}{ Synthetic peptides in clinical use } & Octreotide & $>1000$ & $0.4-2.1$ & $4.4-34.5$ & $>1000$ & $5.6-32$ \\
\hline & Lanreotide & $>1000$ & $0.5-1.8$ & $43-107$ & $>1000$ & $0.6-14$ \\
\hline & Pasireotide & 9.3 & 1 & 1.5 & $>100$ & 0.16 \\
\hline \multirow{2}{*}{ Synthetic peptides in clinical trials } & Vapreotide & $>1000$ & $0.2-5.4$ & 31 & 45 & 0.7 \\
\hline & Somatoprim & $>1000$ & 3 & $>100$ & 7 & 6 \\
\hline \multirow{10}{*}{ Synthetic peptides in experimental use } & Seglitide & $>1000$ & $0.1-1.5$ & $27-36$ & $>1000$ & $2-23$ \\
\hline & BIM-23268 & 18.4 & 15.1 & 61.6 & 16.3 & 0.37 \\
\hline & BIM-23745 & 42 & $>1000$ & $>1000$ & $>1000$ & $>1000$ \\
\hline & BIM-23926 & 4 & $>1000$ & $>1000$ & $>1000$ & $>1000$ \\
\hline & BIM-23120 & $>1000$ & 0.34 & 412 & $>1000$ & 213,5 \\
\hline & BIM-23206 & $>1000$ & 166 & $>1000$ & $>1000$ & 2.4 \\
\hline & BIM-23704 & 6.3 & 1.4 & 43.2 & $>1000$ & 115 \\
\hline & BIM-23190 & $>1000$ & 0.35 & 215 & $>1000$ & 11.2 \\
\hline & BIM-23A799 & 2.5 & 0.3 & 0.6 & $>1000$ & 0.6 \\
\hline & KE108 & 2.6 & 0.9 & 1.5 & 1.6 & 0.65 \\
\hline \multirow{5}{*}{ Nonpeptide agonists } & L-797,591 & 1.4 & 1875 & 2240 & 170 & $>1000$ \\
\hline & L-779,976 & $>1000$ & 0.05 & 729 & 310 & $>1000$ \\
\hline & L-796,778 & $>1000$ & $>1000$ & 24 & $>1000$ & $>1000$ \\
\hline & L-803,087 & 199 & $>1000$ & 1280 & 0.7 & $>1000$ \\
\hline & L-817,818 & 3.3 & 52 & 64 & 82 & 0.4 \\
\hline \multirow{3}{*}{ Chimeric SST/DA compounds } & BIM-23A757 ${ }^{\mathrm{a}}$ & ND & 0.58 & ND & ND & 104.4 \\
\hline & BIM-23760 & 622 & 0.03 & 160 & $>1000$ & 42 \\
\hline & BIM-23A761 ${ }^{\mathrm{c}}$ & ND & 0.01 & ND & ND & 3.7 \\
\hline \multirow{3}{*}{ Antagonists } & ODN-8 & $>10000$ & $>10000$ & 6.7 & $>10000$ & $>10000$ \\
\hline & BN81658 & $>1000$ & $>1000$ & 1.58 & $>1000$ & $>1000$ \\
\hline & Cyn154806 & $>1000$ & 3.6 & 150 & 650 & 20 \\
\hline
\end{tabular}

High affinity for individual SST receptors is reported in bold.

D2R IC 50 : ${ }^{\mathrm{a}} 7.9,{ }^{\mathrm{b}} 15,{ }^{\mathrm{c}} 27 \mathrm{nM}$, ND: not determined.

chromosomes 4, 17, 22, 20, and 16), except for sst2 existing in two splice variants which differ in the length of the carboxyl terminus: a long variant of 369-a.a. (sst2A) and a shorter one of 346-a.a. (sst2B) [1,5]. Recently, novel truncated functional isoforms of sst 5 have been identified $[6,7]$ in humans and mice.

On the basis of sequence identity and pharmacological features, two subfamilies of SST receptors were described: the first class, including sst2, sst3, and sst5, binds synthetic SST analogs such as octreotide and lanreotide, whereas components of the second group, sstl and sst4, do not interact with these agonists [8]. This has relevant implications in SSTbased diagnostic imaging and pharmacological approaches.

Cortistatin (CST), a novel neuropeptide of the SST family, was cloned in 1997 [9]. Two different mature CST peptides of 14 and 29 a.a., derived from the processing of a human precursor (pre-pro-CST), were identified (CST-14 and CST29, respectively), CST binds all five SST receptors with similar affinity (Table 1) and CST-14 and shares 11 of the 14 amino acids of SST-14, as well as many physiological effects, such as neuroendocrine activity (inhibition of GH release), regulation of sleep rhythms, memory process, locomotion, and modulation of the immune system $[10,11]$. More recently, two putative CST receptors, that do not bind SST were also identified: MrgX2 (MAS-related gene X2) receptor [12] and GHS-R1a (growth hormone secretagogue receptor 1a) [13], whose biological function is still not completely characterized.

\section{Somatostatin Receptor Expression and Functions in Normal Tissues}

SST receptors are differentially expressed in discrete or overlapping distribution in multiple target organs, such as central nervous and immune systems, pituitary, thyroid, and adrenal glands, pancreas, gut, and kidney. This complex pattern of SST receptor expression includes coexpression of 
TABLE 2: Main signalling systems regulated by the activation of SST receptors.

\begin{tabular}{|c|c|c|c|c|c|}
\hline & sst1 & sst2 & sst3 & sst 4 & sst5 \\
\hline \multicolumn{6}{|l|}{ cAMP production } \\
\hline Adenylyl cyclase & $\nabla$ & $\nabla$ & $\boldsymbol{\nabla}$ & $\boldsymbol{\nabla}$ & $\nabla$ \\
\hline \multicolumn{6}{|l|}{ Tyrosine phosphatases } \\
\hline $\mathrm{PTP} \eta$ & $\Delta$ & $\Delta$ & $\Delta$ & $\Delta$ & $\Delta$ \\
\hline SHP-1 & $\circ$ & $\Delta$ & $\Delta$ & $\circ$ & $\Delta$ \\
\hline SHP-2 & $\Delta$ & $\Delta$ & $\Delta$ & $\Delta$ & $\Delta$ \\
\hline \multicolumn{6}{|l|}{ Ion channels and transporters } \\
\hline $\mathrm{Ca}^{2+}$ channels & $\boldsymbol{\nabla}$ & $\boldsymbol{\nabla}$ & $\circ$ & $\circ$ & $\boldsymbol{\nabla}$ \\
\hline $\mathrm{K}^{+}$currents & $\Delta$ & $\Delta$ & $\Delta$ & $\Delta$ & $\Delta$ \\
\hline $\mathrm{Na}^{+} / \mathrm{H}^{+}$exchanger 1 (NHE1) & $\boldsymbol{\nabla}$ & $\boldsymbol{\nabla} / \mathbf{\Delta}$ & $\circ$ & $\Delta$ & $\circ$ \\
\hline \multicolumn{6}{|l|}{ MAPK } \\
\hline ERK1/2 & $\nabla / \Delta$ & $\boldsymbol{\nabla} / \mathbf{\Delta}$ & $\boldsymbol{\nabla}$ & $\Delta$ & $\nabla$ \\
\hline p38 & $\circ$ & $\boldsymbol{\Delta}$ & $\circ$ & $\Delta$ & $\circ$ \\
\hline JNK & $\circ$ & $\boldsymbol{\nabla}$ & $\circ$ & $\circ$ & $\Delta$ \\
\hline \multicolumn{6}{|l|}{ Tyrosine kinases } \\
\hline c-Src & $\Delta$ & $\Delta$ & $\circ$ & $\circ$ & $\circ$ \\
\hline JAK2 & $\Delta$ & $\Delta$ & $\circ$ & $\circ$ & $\circ$ \\
\hline \multicolumn{6}{|l|}{ Phospholipid kinases } \\
\hline PI3K & $\boldsymbol{\nabla} / \mathbf{\Delta}$ & $\boldsymbol{\nabla} / \mathbf{\Delta}$ & $\circ$ & $\circ$ & $\circ$ \\
\hline \multicolumn{6}{|l|}{ Cyclin-dependent kinase inhibitors } \\
\hline $\mathrm{p} 27^{\mathrm{kipl}}$ & $\boldsymbol{\Delta}$ & $\boldsymbol{\Delta}$ & $\circ$ & $\circ$ & $\circ$ \\
\hline $\mathrm{p} 21^{\mathrm{Cip} 1}$ & $\Delta$ & $\circ$ & $\circ$ & $\circ$ & $\circ$ \\
\hline Zacl & $\circ$ & $\Delta$ & $\circ$ & $\circ$ & $\circ$ \\
\hline \multicolumn{6}{|l|}{ Nitric oxide synthases } \\
\hline nNOS & $\circ$ & $\Delta / \nabla$ & $\boldsymbol{\nabla}$ & $\circ$ & $\nabla$ \\
\hline eNOS & $\boldsymbol{\nabla}$ & $\nabla$ & $\boldsymbol{\nabla}$ & $\circ$ & $\circ$ \\
\hline \multicolumn{6}{|l|}{ Apoptotic pathways } \\
\hline p53 & $\circ$ & $\circ$ & $\Delta$ & $\circ$ & $\circ$ \\
\hline BAX & $\circ$ & 。 & $\Delta$ & $\circ$ & $\circ$ \\
\hline Bcl-2 & $\circ$ & $\circ$ & $\boldsymbol{\nabla}$ & $\circ$ & $\circ$ \\
\hline
\end{tabular}

$\mathbf{\Delta}$ : activation, $\mathbf{\nabla}$ : inhibition, o: no effects.

multiple subtypes in a tissue-specific pattern and distinct physiological roles [14].

SST receptors are widely expressed throughout the brain: in particular, sstl and sst2 have a diffuse localization, whereas sst 4 and sst5 show a more confined expression in hippocampus and hypothalamus, respectively [15]. Moreover, in different brain regions, sst1 is also localized presynaptically, controlling SST release from somatostatinergic neurons [16]. Starting from animal studies showing a positive modulation of exogenous administered SST on memory retention $[17,18]$, and the reduction of SST expression during aging [19], recent evidence proposed a key role of SST neuron dysfunction in Alzheimer's disease and other brain disorders associated with cognitive impairment (for a review see [2]). Interestingly, SST receptors also affect glial function, for example controlling IL-6 secretion from astrocytes [20]. SST receptors are also localized in the peripheral nervous system, in proximity of pain terminals, where they were reported to play a role in nociception [21].

At pituitary gland level, sst1 and sst5 mainly control GH and prolactin secretion while sst 2 is involved in the release of $\mathrm{GH}, \mathrm{TSH}$, and ACTH [1].
In the immune system, SST acts as autocrine/paracrine factor within the complex cellular structure of lymphoid organs. The presence of SST and its receptors was established in cells mediating inflammation and immune response such as $\mathrm{B}$ and $\mathrm{T}$ lymphocytes and in monocytes, but not granulocytes and the specific expression of sst 3 on peripheral human $\mathrm{T}$ lymphocytes seems to vary with species and with the origin of $\mathrm{T}$ cells [22]. sst1, sst2, and sst3 were identified in thymus with a higher expression of sst2 in immature thymocytes $\left(\mathrm{CD}^{+} / \mathrm{CD}^{-}\right)$and sst 3 mainly in more mature cells $\left(\mathrm{CD}^{+}\right)$. Immune response and neuroendocrine regulation occurs at multiple levels and, among different immunoregulatory peptides, SST is involved in the control of cell growth and migration [23]. CST also is involved in the modulation of inflammatory response, acting as endogenous anti-inflammatory neuropeptide. CST is produced by T cells, macrophages and monocytes in response to inflammation, injuries, or antigen stimulation and, through the binding to both sst1-5 and ghrelin receptors expressed on immunocompetent cells, inhibits the release of inflammatory factors, chemokines, $\mathrm{T}$ cell proliferation, and $\mathrm{T}$ helper cell response and stimulates IL-10 production and regulatory T cells [24]. 
In the gastrointestinal tract, the mucosal delta-cells are one of the major sources of SST in the gut influencing motility, secretion and absorption [25]. At the pancreatic level, both sst1 and sst5 are highly expressed in insulin-releasing beta-cell, sst5 in the SST-releasing delta-cells and sst 2 mainly in glucagon secreting alpha-cells. On the contrary, sst3 and sst 4 are poorly expressed. In intestinal cells, sst 5 controls the release of glucagon-like peptide-1 (GLP-1).

\section{Somatostatin Receptor Signal Transduction, Homo- and Heterodimerization, and Trafficking}

The different physiological effects of SST in different tissues are mainly ascribed to the specific characteristics of the cell types that express the SST receptors, resulting in the activation of distinct signal transduction pathways. In detail, the inhibition of adenylyl cyclase activity and the reduction of intracellular $\mathrm{Ca}^{2+}$ levels through the coordinated activities on different $\mathrm{K}^{+}$and $\mathrm{Ca}^{2+}$ channels, are responsible of the antisecretory effects of SST, while the activation of phosphotyrosine phosphatases (PTPs), and in particular of three enzymes of this family: Src-homology phosphatase type 1 (SHP-1) and type 2 (SHP-2), and density-enhanced phosphatase 1 $(\mathrm{DEP}-1) / \mathrm{PTP} \eta$, and the modulation of mitogen-activated protein kinase (MAPK) activity, are mainly responsible of SST antiproliferative effects [26-43]. Both adenylyl cyclase inhibition and PTP activation are induced by all SST receptor subtypes, while MAPK activity is increased by sst 4 , decreased by sst 3 and 5 , and modulated in both directions by sst 1 and 2 . Moreover, SST/receptor interaction acts on $\mathrm{K}^{+}$and voltagegated $\mathrm{Ca}^{2+}$ channels, $\mathrm{NA}^{+} / \mathrm{K}^{+}$exchanger, cyclooxygenase- 2 and (sst2 and 5), and phospholipase A2 (sst1 and 2) activities $[44,45]$.

An overview of the signaling pathways activated by SST receptors is summarized in Figure 1 and Table 2.

The role of specific SST receptor subtypes in SST antiproliferative effects have been identified, since sst1, 2, 4, and 5 are mainly involved in the arrest of cell cycle progression, while sst 2 and 3 are also able to activate proapoptotic pathways, as well as anti-angiogenic signals, an indirect control of tumor growth $[44,45]$.

Homo- and/or heterodimerization of all GPCR family, including SST receptors, play(s) a fundamental role in ligand binding, receptor expression, trafficking and desensitization, and signal transduction [46] due to distinct biological features of the native monomeric isoforms. The functional interactions among individual human SST receptors have been extensively investigated [47] as well as the dimerization with different components of SST receptor family or with other GPCRs [48, 49] (see Figure 2). Dimerization was shown to be either constitutive or ligand-dependent and, despite high structural homology, SST receptor subtypes show marked dimerization heterogeneity and differences between different species. sst1 is the only SST receptor existing as monomer, regardless agonist binding [50]. In basal conditions, sst2 and sst 3 exist as homodimers but, in response to agonists, dissociate to monomers that are rapidly internalized for sst2, while monomers of sst 3 are retained in membrane [51]. On the contrary, basal sst 4 homodimers are enhanced after ligand treatment [52]. sst5 is monomeric and displays dimerization upon agonist binding in a concentration-dependent manner.

SST receptor subtypes, coexpressed in the same cells, can also form heteromeric complexes within SST receptors, or heterodimerize with members of different GPCR family (i.e., dopamine, opioid, or adrenergic receptors). sst1/sst5, sst2/sst3, and sst4/sst5 heterodimerizations have been described, although these studies mainly refer to heterologous cell models (CHO-K1 or HEK-293) transfected with specific SST receptor subtypes $[49,51]$.

Among the interactions of SST receptors with components of other GPCR families, those with dopamine 2 receptor (D2R) have been widely investigated for their potential therapeutic implications [53]. In fact, SST receptors and D2R are frequently coexpressed in endocrine and pituitary tumors [54] and both receptor activations lead to inhibition of hormonal secretion and cell proliferation. In vitro receptortransfected models showed that D2R preferentially forms heteromeric complexes with sst 2 and sst5 [48, 49]. These results were confirmed in non-endocrine tumor cells, natively expressing SST receptors and D2R. It was shown that these receptors can interact in the absence of agonists [55] and the treatment with the chimeric compound targeting both receptor types (BIM-23A760) significantly increased the sst5/D2R and sst2/D2R dimers.

A cross-talk between SST receptors and growth factor tyrosine kinase receptors (RTKs) (e.g., epidermal growth factor receptor, EGFR) has been recently described [4], resulting in sstl or sst1/5 dimers binding to EGFR to negatively regulate EGF-mediated effects $[3,56]$. The relevance of heterodimerization between SST receptors and EGFR is mainly due to the involvement of this RTK in mitogenic signaling and oncogenic transformation, as SST receptors may competitively bind to EGFR, interfering with its phosphorylation and activation of signaling pathways responsible of cancer development [4]. In fact, it was described that in pancreatic cancer cells activation of SST receptors results in a PTP-dependent, pertussis toxin-sensitive dephosphorylation of EGFR [57].

As previously discussed, SST receptor trafficking (endocytosis, recycling or degradation) after agonist binding is well documented [58]. On the contrary, less is known about functional SST receptor travelling along the secretory pathway to the plasma membrane. Upon agonist activation, SST receptors undergo phosphorylation through G-proteincoupled receptor kinase (GRK) and bind $\beta$-arrestin- 1 and -2 that trigger the desensitization process by blocking coupling between the receptor and G proteins [59]. Phosphorylated receptors are then internalized into clathrin-coated vesicles and directed to endosomes, where they are dephosphorylated by specific serine/threonine phosphatases. Dephosphorylated SST receptor complexes can be recycled/resensitized on cell membrane [60] or degraded in different intracellular compartments.

Individual SST receptors have different internalization rates (internalization is higher for sst 2,3 and 5 than for sst1 and 4) [61], since their interaction with $\beta$-arrestins results 


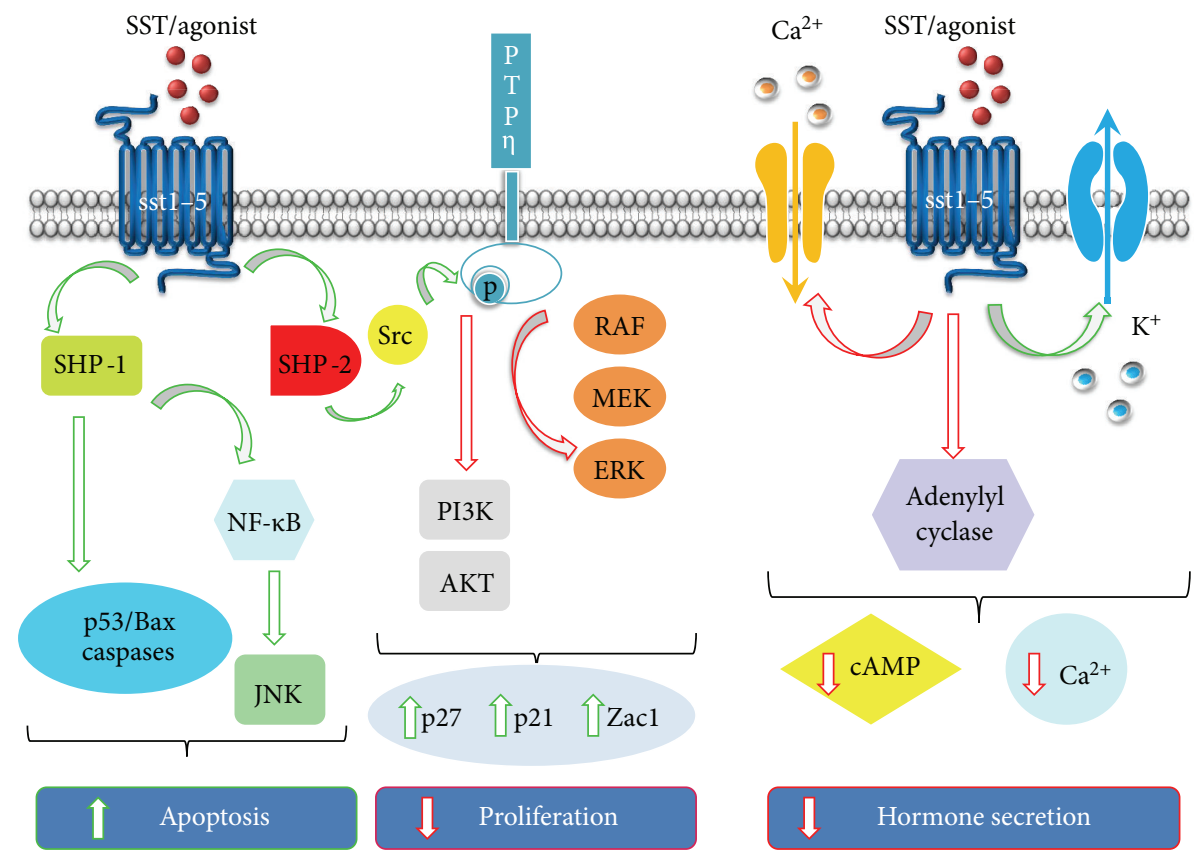

FIGURE 1: Schematic representation of the intracellular signaling pathways modulated by somatostatin receptors. Antiproliferative effects of somatostatin (SST) and its analogs; SST and analogs binding to SST receptors activate different phosphotyrosine phosphatases (PTPs) SHP-1 and SHP-2 and PTP $\eta$. Activated SHP-1 triggers intracellular proapoptoptic signals involving the induction of caspase activation and p53/Bax. SHP-1 also cause apoptosis by activation of the transcription factor NF- $\kappa$ B leading to the inhibition of the MAP kinase JNK anti-apoptotic effects. SHP-2 activates Src that directly interacts with PTP $\eta$ inducing its phosphorylation in tyrosine and activation. PTP $\eta$ dephosphorylates intracellular effectors involved in the control of cell cycle progression, such as the ERK and the PI3K/Akt pathways, causing the upregulation of the cyclin kinase inhibitors $\mathrm{p} 21^{\mathrm{cip} 1 / \text { waf1 }}$ and $\mathrm{p} 27^{\mathrm{kip} 1}$ and the tumor suppressor gene Zacl. As a result, cells accumulate in G1 phase without entering S-phase and cell proliferation is blocked. Antisecretory effects of SST and its analogs; SST inhibits the secretion/synthesis of many hormones through the inhibition of voltage-dependent $\mathrm{Ca}^{2+}$ channels and activation of $\mathrm{K}^{+}$channels, decreasing intracellular $\mathrm{Ca}^{2+}$ concentration, and inhibition of adenylyl cyclase, lowering intracellular cAMP levels. Activated pathway: green arrows; inhibited pathway: red arrows.

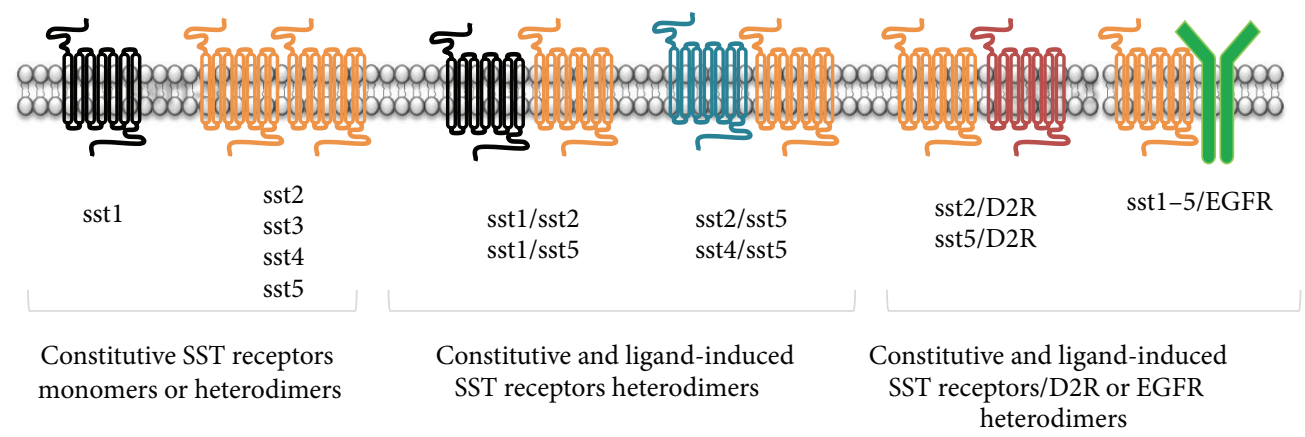

FIGURE 2: Dimerization pattern of somatostatin receptors. Each SST receptor subtype show a different constitutive tendency to dimerize. sst1 exists as a monomer while sst2, 3, 4 and 5 homo-dimerization occurs both constitutively or after somatostatin binding. SST receptors may form heterodimers with other member of SST receptor family, either in resting conditions or upon ligand binding. SST receptors also dimerize with receptors of other GPCR families, (e.g., D2R) or with other receptor families, such as tyrosine kinase receptors (i.e., EGFR), originating heterodimers.

in receptor/arrestin complexes with lower or higher stability. This specific feature influences SST receptor fate: sst2 and 5 are faster recycled while sst3 commonly undergoes degradation $[61,62]$. In addition, diverse SST analogs may affect SST receptor trafficking in different ways, as demonstrated by the SST agonist pasireotide that either causes sst 2 membrane recycling [63] or does not affect its internalization [64], whereas octreotide mainly induces sst 2 internalization.
Importantly, starting from this evidence, a very recent study [65], evaluating the ability of different SST analogs to induce SST receptors internalization, was able to classify them as agonists, partial agonists, or antagonists toward sst2 3 and 5, through the determination of receptor biological responses instead of evaluating only binding affinity. Unexpectedly, in this experimental model, pasireotide (showing high affinity binding for sst1, 2, 3, and 5) was able 
to activate sst 3 and 5 but acted as partial agonist at the sst2 [65]. Octreotide (able to bind with high affinity sst2 and 5) exhibited agonistic properties for sst2 but failed to activate sst5. Finally, the recently introduced SST analogs, somatoprim (that binds with high affinity to sst2, 4 and 5) was a full agonist for both sst2 and sst5 [65]. Thus, it was proposed that a reevaluation of specific effects of SST agonists toward each subtype should be performed, although homo- and heterodimerization could further complicate the analysis.

\section{Somatostatin Analogs}

The biological effects induced after SST receptor activation allowed their identification as relevant drug targets. However, the main limit in using native SST for in vivo therapy is the very short half-life of this peptide. Thus, to prolong the biological activity of SST many analogs have been synthesized, showing a prolonged persistence in the organism and often endowed of increased potency. Among them, the first octapeptide developed was octreotide, which reaches a half-life of 90-120 min after subcutaneous administration, followed by lanreotide, and vapreotide, also being cyclooctapeptide SST analogs [1].

Primary structures of native SST-14 and of the most relevant synthetic analogs are reported in Figure 3, and the calculated $\mathrm{IC}_{50}$ toward individual SST receptor subtypes of all these compounds is reported in Table 1.

A common pattern of SST receptor binding ability is shared by these analogs: high affinity for sst 2 and sst5, medium/low affinity for sst3, and lack of binding to sst1 and sst4 [1].

Octreotide and lanreotide are currently approved for the treatment of GH-secreting pituitary adenomas. More recently, improved formulations of the above molecules were introduced in clinical use, such as octreotide long-actingrelease (LAR), lanreotide-sustained-release and lanreotide autogel, that improved the pharmacokinetic parameters allowing a single administration every 14 or 28 days $[66,67]$.

The possibility of a selective modulation of a single SST receptor subtype, to inhibit specific biological functions, represents an attractive pharmacological feature to obtain therapeutic specificity. A number of monospecific SST receptor subtype analogs were developed being either peptidomimetic compounds [68] or peptides, such as sstl-specific (BIM23745 and BIM-23926) sst2-selective (BIM-23197 and BIM23120), and sst5-specific (BIM-23268 and BIM-23206). These compounds were reported to mediate both antisecretory and antiproliferative activity in experimental models [69].

More recently, based on molecular investigations of cell SST receptor expression profile showing in most cases coexpression of multiple receptors, it was developed the concept that a better pharmacological response could be obtained through the simultaneous activation of all the receptors in a given tissue. This assumption led to the identification of novel compounds able to bind simultaneously two SST receptors with higher affinity than reference drugs (octreotide and lanreotide). Among them the bispecific molecules BIM23704 (sst1 and 2) and BIM-23244 (sst2 and 5) were used in several preclinical studies $[69,70]$. Subsequently, multireceptor binding analogs (i.e., pasireotide (SOM230), somatoprim, KE108, and BIM-23A779) were developed to overcome octreotide resistance in acromegaly and carcinoid tumors and to increase sensitivity in pathologies of tissues expressing SST receptors other than sst2 [71-73]. In this group pasireotide is one of the newest multi-receptor ligand analog, exhibiting a prolonged half-life, and high affinity for sst1, 2, 3 and 5, with 30-to-40-fold higher affinity for sst1 and 2 than octreotide or lanreotide $[73,74]$. Pasireotide represents a promising candidate for octreotide resistant or lanreotide low-responsive tumors [75]. Therefore, at the end of a 12-months phase III study, pasireotide has been approved for Cushing's disease [76], and it is currently in phase III clinical trials for acromegalic patients and phase II trials for neuroendocrine tumors (NETs).

Other pan-SST receptor agonists are currently under development: the hepta-backbone cyclic peptide somatoprim (DG3173), which is currently under clinical and preclinical evaluation, KE108 with a reduced size and stabilized structure, and BIM-23A779 (see Table 1) [71, 77]. Somatoprim exhibits a unique binding profile in that binds with high affinity to sst2, 4 and 5 but not sstl and 3 [78].

Several potent and selective sst 4 binding peptides and nonpeptide compounds have been synthesized. Among them TT-232, a hepta-peptide sst 4 and sst1 agonist, and J-2156, sst4-selective compound, have shown anti-inflammatory, antinociceptive and antitumor effects [79-81].

Although less-represented sst3 agonists and antagonists have been also synthesized: BIM-23056 is a sst3 agonist with antagonist activity for sst5, analogs with replacement of the tryptophan residue by one of the two enantiomers of 3-(31quinolyl)-alanine binds sstl and 3 [82], while BN81658, is a selective sst3 antagonist [83].

Chimeric compounds able to bind both SST and dopamine (DA) receptors were synthesized, on the basis of simultaneous presence and heterodimerization of these receptors on the same normal and tumor cells in pituitary gland and gastrointestinal tract, and on the clinical evidence that the cotreatment with octreotide and the DA agonist bromocriptine inhibits $\mathrm{GH}$ secretion in acromegalic patients more efficiently than the single agents $[54,84]$.

The compound BIM-23A387, selective for sst2/D2R, showed the in vitro ability to strongly block GH and PRL release in human pituitary cells as compared to sst2- and D2R-monospecific analogs [85]. Hormonal hypersecretion is efficiently controlled also by sst2/D2R-high-affinity/sst5low-affinity chimeric molecule BIM-23A760 [53, 77]. These molecules tested in a non-small lung cancer cell line, and in a prostate cancer cell line showed a greater antiproliferative effect than subtype specific SST and DA agonists, alone or in combination $[55,86]$, and in the control of cell growth from primary cultures of human nonfunctioning pituitary adenomas [53]. However, recently, a phase II trial with BIM-23A760 in acromegaly was stopped due an unexpected time-dependent accumulation of metabolites that impaired the activity of the native molecule [87]. 
SST-14

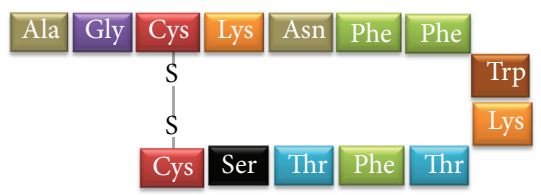

Lanreotide
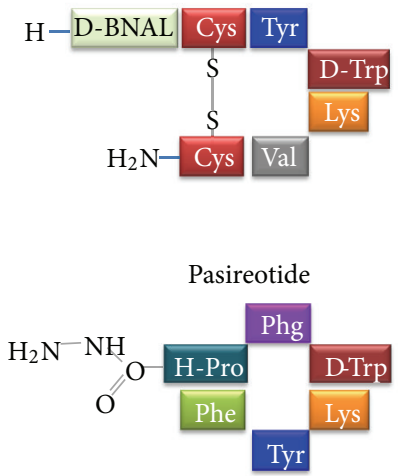

Octreotide

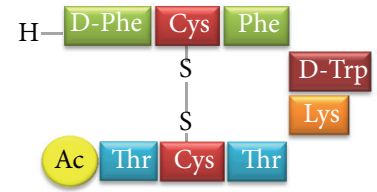

Vapreotide

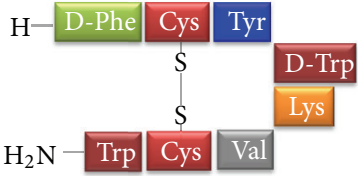

Somatoprim

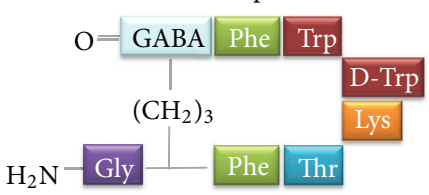

FIgURE 3: Amino acid composition of somatostatin 14 (SST-14) and of the main synthetic analogs (octreotide, lanreotide, vapreotide, pasireotide, and somatoprim).

The above data highlight the great efforts and developments achieved in SST receptor-targeted therapy. However further studies are needed to delve deeper the pathophysiological role of SST receptor homo- and heterodimerization, trafficking, and their cell and tissue specificity as factors that may influence SST analogs clinical responses to develop more efficacious and selective drugs.

\section{Radioactive Somatostatin Analogs for Imaging and Therapy}

Radiolabeled peptides have acquired increasing interest in nuclear medicine for tumor diagnosis, staging, therapy (peptide receptor radionuclide therapy, PRRT) and followup. In particular, the use of SST analogs as radiolabeled peptides is a powerful diagnostic tools for in vivo tumor imaging, since, after intravenous injection they accumulate in SST receptor-expressing tumors [88]. In parallel, due to the cytotoxicity of radiolabeled SST analogs, an emerging and effective treatment strategy is SST-based PRRT.

Diagnostic SST radioisotopes allow the localization of SST receptor expressing tissues and identify patients for subsequent radionuclide therapy. The structure of these labeled peptides includes a chelator (e.g., diethylenetriaminepentaacetic acid, DTPA, or 1,4,7,10-tetraaza-cyclododecane1,4,7,10-tetraacetic acid, DOTA) that forms a stable complex with the radiometal-conjugated SST analogs. These three elements (chelator, radiometal, and SST analog) strongly influence the efficacy of imaging and therapy, affecting receptor binding affinity, internalization rate, and in vivo label stability; thus, the development of novel radiopeptides focused on the improvement of these properties to obtain suitable compounds. $\left[{ }^{111}\right.$ In]-DTPA-octreotide retains high affinity for sst2 and has been used for scintigraphic imaging for primary and metastatic neuroendocrine tumors (NETs), improving the sensitivity of standard diagnostic modalities [89]. It was further optimized by molecules as DOTA-d-Phe1-Tyr3octreotide (DOTATOC), DOTA-d-Phel-Tyr3-octreotate (DOTATATE), characterized by higher sst2 affinity, and DOTA-1-NaI Tyr3-octreotide (DOTANOC) that also binds sst3 and sst5. More recently, the availability of positron emitters $\left(\left[{ }^{68} \mathrm{Ga}\right]\right.$ and $\left[{ }^{18} \mathrm{~F}\right]$ ) labeled analog (DOTATOC) allowed its application to positron emission tomography (PET) imaging [90], overcoming weakness of $\gamma$-radiation emitters for SPECT as of [ $\left.{ }^{111} \mathrm{In}\right]-\mathrm{DTPAOC}$ (Octreoscan) in the detection of metastatic NETs [91, 92].

In endocrine tumors, PRRT with SST analogs was initially performed using $\left[{ }^{111} \mathrm{In}\right]$-coupled peptides, then replaced by DOTA stably labeled with $\left[{ }^{68} \mathrm{Ga}\right],\left[{ }^{90} \mathrm{Y}\right]$, or $\left[{ }^{177} \mathrm{Lu}\right]$. These compounds were well tolerated and efficacious in controlling symptoms and prolonged patient survival [93]. In a large study on 504 NET patients treated with the radiolabeled SST analog $\left[{ }^{177} \mathrm{Lu}-\mathrm{DOTA}, \mathrm{Tyr}_{3}\right]$-octreotate [90], an overall survival benefit was evident when the outcome was compared with the historical data of the group. Imhof et al. [94] reported a phase II study on a large series of patients with metastasized neuroendocrine cancers treated with repeated cycles $\left[{ }^{90} \mathrm{Y}\right.$ DOTA]-TOC reporting that response is associated with longer survival.

Currently, single radioisotope therapy is the standard PPRT practice, however preclinical study in rats bearing pancreatic cancer, showed that the association of $\left[{ }^{77} \mathrm{Lu}\right]$ - and $\left[{ }^{90} \mathrm{Y}\right]-\mathrm{SST}$ analogs exerts higher antitumor efficacy than single radionuclides [93]. Another study, evaluating the effectiveness of SST-based radiopeptide therapy 
using single radioisotope versus a combination of compounds in patients with NET metastatic cancers showed that the combination of $\left[{ }^{90} \mathrm{Y}-\mathrm{DOTA}\right]-\mathrm{TOC}+\left[{ }^{177} \mathrm{Lu}-\mathrm{DOTA}\right]-$ TOC radiopeptides improved overall survival as compared with [ ${ }^{90}$ Y-DOTA]-TOC alone, while comparable toxicity was observed in the two groups [95].

Radiopeptides used in clinics are SST agonists, mainly octreotide, on the basis of their high-affinity binding and the induction of internalization of the ligand-receptor complex that leads to intracellular accumulation of the radioligand [96]. However, preclinical in vivo studies showed that sst2- and sst3-expressing tumors have higher uptake of radiolabeled SST antagonist, as demonstrated by the evaluation of the labeled antagonist $\left[{ }^{111} \mathrm{In}\right]$-DOTA-sst3-ODN-8 in a mouse model bearing sst3 expressing tumor and by in vitro experiments with $\left[{ }^{111} \mathrm{In}\right]$-labeled sst2 antagonist DOTA-sst2-ANT ([ $\left.{ }^{111} \mathrm{In}\right]-$ DOTA-[4-NO $\mathrm{N}_{2}$-Phec(DCys-Tyr-DTrp-Lys-Thr-Cys)-DTyr$\mathrm{NH}_{2}$ [97, 98]. Recently, bicyclic SST-based analogs have been proposed as potential radiopeptides for SPECT/PET on NETs [99].

Other radioantagonists were developed for PET in sst2positive tumors as $\left[{ }^{64} \mathrm{Cu}\right]$ and $\left[{ }^{68} \mathrm{Ga}\right]$ antagonists coupled with different chelators [4,11-bis(carboxymethyl)-1,4,8,11-tetraazabicyclo [6.6.2] hexadecane (CB-TE2A), 1,4,7-triaza-cyclononane,1-glutaric acid-4,7-acetic acid (NODAGA), and DOTA] showing a higher uptake and image contrast on PET scans [99].

A recent pilot study is evaluating the clinical feasibility of imaging with the SST receptor antagonist [ $\left.{ }^{111} \mathrm{In}\right]-\mathrm{DOTA}-\mathrm{pNO} \mathrm{NO}_{2}$-Phe-c(DCys-Tyr-DTrp-Lys-Thr-Cys) $\mathrm{DTyrNH}_{2}$ ([ $\left.\left.{ }^{111} \mathrm{In}\right]-\mathrm{DOTA}-\mathrm{BASS}\right)$ in patients with NETs [100].

Beside NETs, SST-based tracers ([ $\left.{ }^{111} \mathrm{In}\right]$-pentetreotide) may represent a diagnostic tool in tumors expressing sst2, 3 , and 5, such as meningiomas, gliomas, Hodgkin and nonHodgkin lymphomas, and metastases from breast cancer [101]. In other lesions (pheochromocytomas and medullary thyroid carcinomas) a definite usefulness of radiolabeled SST analogs is still not proven, mainly due to their limited detection rate [102, 103]. Similarly, conflicting results using [ $\left.{ }^{111} \mathrm{In}\right]$-DTPA-octreotide in pituitary adenomas were reported [103]. Few case-report studies demonstrated the efficacy and safety of radiolabeled SST-analogs in pituitary metastasis in a patient with NET [104] and in a case of relapsed prolactin-secreting giant pituitary adenoma [105].

Thus SST receptor targeting with radiolabeled analogs is an important development, particularly in NET imaging and therapy, and radiopeptide translational research may support innovative therapeutic modalities [106, 107].

\section{Somatostatin Receptor Signaling in Tumor Cells}

SST receptors are commonly expressed in tumors including both endocrine (pituitary adenoma, neuroendocrine and gastropancreatic neoplasms, thyroid, adrenal, and small cell lung carcinomas) and nonendocrine (gliomas, meningiomas, breast, and ovarian cancers, osteosarcomas) histotypes. Generally, sst2 is the subtype most widely expressed and sst3 and sst 4 the less expressed in human cancers. Although in most cases all subtypes can be identified in tumor cells a tumor-specific pattern of expression can be identified in some cases. For example, sst 2 and sst5 are the receptors more frequently detected in $\mathrm{GH}$-secreting pituitary adenomas, while sst 3 is frequently expressed, altogether with sst 2 and 5, in nonfunctioning pituitary adenomas [108].

SST ability of inhibiting tumor growth and metastatic spread involves SST receptor activation located on both cancer and microenvironment cells, particularly endothelial cells of tumor vessels responsible of the neovascularization of the tumor.

The antitumor activity of SST and its analogs is mediated by multiple SST receptors, through direct antiproliferative (inhibition of mitogenic stimuli of growth factors, arrest of cell cycle) and proapoptotic signals and, indirectly, inhibiting the secretion of proliferative and angiogenic growth factors and hormones or affecting neoangiogenesis at endothelial cell level [44].

SST controls cancer cell proliferation via the interference with different signaling pathways (PTPs, JAK2, Ras/ERK, and $\mathrm{Pi} 3 \mathrm{~K} / \mathrm{Akt}$ ) resulting in cytostatic effects mediated by the induction of involving the induction of cell cycle inhibitors p27 or p21, or tumor suppressors, like Zac1 [33, 109-112].

Studies using cells transfected with individual SST receptor subtypes, or using selective agonists in cell natively expressing multiple SST receptors, showed that all 5 receptor activations induce PTP activity [27, 37, 40, 57, 69, 113, 114]. To date, a subset of PTPs, namely, the cytosolic SHP1, SHP2, and the transmembrane PTP $\eta$, are considered the main effectors of the antiproliferative activity of SST. These enzymes, upon activation, through the modulation of several transduction mechanisms, target tyrosine residues of specific substrates regulating proliferative pathways (ERK1/2 PI3 K/AKT, NO/cGMP, etc.) [110, 115-119].

Arrest of cell proliferation, related to SST receptor activation of SHP1, was reported in different tumor cell lines derived from pituitary adenomas (GH3) and breast (MCF7), pancreatic (MIA-PaCa, PANC-2, PC-1, PC-3, AR4-2J), and thyroid medullary (TT) carcinomas [110, 114, 120-124]. In co-immunoprecipitation experiments, sst2 and SHP-1 were identified in a multiprotein complex regulated by $\mathrm{Gi} 3 \alpha$ [125]. Octreotide activation of sst 2 caused the activation of SHP-1 that rapidly dissociates from the receptor, binds to insulin receptor dephosphorylating the receptor itself and its substrates (i.e., IRS-1 and Shc) and leading to a negative modulation of insulin mitogenic signalling [126]. sst 2 antiproliferative effects, characterized by the inhibition of the entry in the $S$ phase and the accumulation of the cells in G1, due to $\mathrm{p} 27^{\mathrm{kip} 1}$ overexpression that sequesters $\mathrm{cdk} 2$ from cyclin $\mathrm{E}$ and induces accumulation of hypophosphorylated retinoblastoma gene product [112]. SST and analogs activation of SHP1 resulted in tyrosine phosphorylation of the PTP, mediated by the cytosolic kinase JAK2 whose activity was identified as an absolute requirement for both sst2-mediated activation of SHP1 and the inhibition of cell proliferation 
[127]. In resting conditions, sst2, JAK2, and SHP1 form a unique signalling complex, but upon SST binding JAK2 dissociates and phosphorylates and activates SHP1 [128]. Moreover, SHP2 and cytosolic tyrosine kinases (c-Src) were also detected in the sst2-associated multieffector complex [128]. Thus, it was proposed a molecular model in which the cytostatic effects of SST, via sst2, are the results of the sequential activation of kinases and phosphatases, with SHP2 phosphorylation by c-Src responsible of SHP1 binding to the receptor and activation (for review see [129]).

SHP2 was also involved in SST effects on cell cycle mediated by sstl activation [28, 33, 40]. In particular, in CHO-K1 cells, solely expressing sst1, SST induced cytostatic effects through a rapid activation of SHP2 and c-Src [33]. SHP2 is expressed in several SST-responsive tumors including gliomas and neuroblastomas as well as in thyroid cells. Its activation by SST receptors causes cell cycle arrest via the inactivation of the tyrosine kinase receptors for EGF, platelet derived growth factor (PDGF) and insulin $[57,109,130]$ and the subsequent inhibition of the growth factor-dependent activation of ras/Raf/ERK1/2 pathway [131]. However, kinetics studies showed that sstl activation in CHO$\mathrm{K} 1$ cells also caused a delayed and long-lasting PTP activity, besides SHP2 whose activation was, on the other hand, rapid and transient [28]. In rat thyroid cells, this activity was associated to the PTP $\eta$ (also called DEP-1 in humans) a membrane bound receptor-like PTP whose activation causes dephosphorylation of ERK1/2. The reduced activity of MAP kinase resulted in a low level of phosphorylation of the CDKI p $27^{\text {kip } 1}$ that, in the unphosphorylated form, cannot be ubiquitinated and degraded by the proteasome [38, 109, 132]. These results were confirmed studying glioma cells, in which SST-activated PTP $\eta$ was able bind active ERK1/2 causing its dephosphorylation/inactivation [133] and the consequent upregulation of $\mathrm{p} 27^{\mathrm{kip} 1}$ [134]. Importantly, in glioma cell lines and primary cultures from human glioblastomas, the cytostatic activity of SST was dependent on the expression and activation of PTP $\eta$. However, while SHP2 is widely expressed in gliomas, $\mathrm{PTP} \eta$ expression is rather inconstant (it was detected in about $1 / 3$ of the human glioblastomas analysed, [133]), and the possibility to activate this PTP by SST agonists was proposed to represent a potential molecular determinant to obtain antiproliferative responses in glioblastomas [133].

Thus, from these studies it was proposed that two classes of PTPs are activated in response to SST: SHP1 and SHP2 that act mainly on activated tyrosine kinase receptors and PTP $\eta$ that mainly acts down-stream the proliferative signalling dephosphorylating ERK1/2. However, in the same way described for sst 2 and SHP1 (see before), the activation of $\mathrm{PTP} \eta$ by sst1 requires the constitution of a multieffector complex, composed of both kinases and PTPs. In these studies using either cells natively expressing sst1 (C6 glioma cells) or $\mathrm{CHO}-\mathrm{K} 1$ cells transfected with this receptor, a large multimeric protein complex occurred in proximity of sstl in resting conditions that, besides the receptor, was composed of the trimeric G-protein, Jak2, SHP2, c-Src, and PTP $\eta$ [135]. Upon SST binding via $\mathrm{G}$ protein activation Jak2 becomes active and phosphorylated SHP2. Upon phosphorylation, SHP2 is also activated, dissociates from the receptor and dephosphorylates the inhibitory tyrosine on c-Src C-terminus. Active c-Src, in turn, phosphorylates PTP $\eta$ causing the sustained activity of this PTP to inactivate ERK1/2 [135].

The identification in different cell models of similar multieffector cascades activated by different SST receptors (sstl and sst2) that, through the interplay of different kinases (Jak2, c-Src) and PTPs (SHP2), leads to the activation of an effector PTP (SHP-1 or PTP $\eta$ ), allowed the definition of a common modular transducing mechanism by which cytostatic effects are induced by SST [129].

Another direct mechanism by which SST controls cell growth is the induction of pro-apoptotic pathways mainly mediated by sst 2 and sst3 and involving SHP-1. Apoptosis may occur via extrinsic (activated by the receptors of the TNF $\alpha$-related apoptosis-inducing ligand), and Fas ligand or intrinsic (mitochondrial) pathways. sst 2 inhibits the $\mathrm{PI} 3 \mathrm{~K} / \mathrm{AKT}$ cascade, the anti-apoptotic protein Bcl-2 and NF$\kappa \mathrm{B}$ transcription factor, while sst3 induces apoptosis via the activation Bax [136-139]. Table 2 summarizes the different pathways of SSTR subtype activation.

Indirect antiproliferative effects of SST involve the inhibition of the GH/IGF-I axis through central (sst2, sst5) and peripheral (sst2, sst3) mechanisms, which via a PTP, dephosphorylate STAT5b and inhibit expression of the hepatic IGF-I [140].

SST receptor expression was observed in peritumoral vessels, mainly in endothelial cells. In particular, sst2 has been found to be uniquely upregulated during the angiogenic switch, from quiescent to proliferative endothelium [141]. Indeed, SST is a powerful inhibitor of neovascularization in several experimental models and, consequently, the inhibition of tumor angiogenesis is considered one of the mechanisms mediating SST antineoplastic effects. Antiangiogenic properties of SST were identified to be mediated by sst 2 and sst 3 activation that results in the blockade of proliferation and migration of endothelial cells and of monocyte activation [142], and the inhibition of the release of proangiogenic factors such as VEGF, PDGF, IGF-1, and bFGF [141]. The effects on endothelial cells were mainly mediated by the inhibition of eNOS and ERK1/2 activities [143]. Inhibition of NO production by both eNOS and nNOS was also described after sst1-3, but not sst4, activation [115] via the interference with different molecular mechanisms involving both classical (PLC activity and PI3k/Akt) and novel (ceramide synthesis) pathways [144].Conversely, nNOS was activated in rat retina by sst 2 agonists via an SHP1-dependent mechanism [145].

Tumor cell invasiveness, a feature characterizing the aggressiveness of malignant tumors, also represents a SST receptor target via the inhibition of the PI3K/Akt pathway and the modulation of proteins responsible of actin filament assembly (namely, Rac and Rho) [146].

\section{Somatostatin and Somatostatin Receptors in Neuroendocrine Tumors}

SST receptors are highly expressed in neuroendocrine tumors (NET, including pituitary adenomas, endocrine pancreatic 
tumors, gastrointestinal and lung carcinoids, small cell carcinomas, thyroid medullary cancer, and others). Pituitary adenomas and gastroenteropancreatic (GEP) NETs represent the major tumor targets for SST analogs presently used in clinical practice.

Pituitary tumors are generally benign slow-growing neoplasms, and different adenomas show a typical pattern of SST receptor expression [74] according to the secreting cells from which they originate: $\mathrm{GH}$-secreting pituitary adenomas mostly express sst2 and sst5 [147], ACTH-secreting lesions predominantly coexpress sst 5 and sst 2 [148] while in prolactinomas sstl and sst5 are the predominant receptors [149]. In clinically nonfunctioning pituitary adenomas sst3 is highly expressed, followed by sst 2 and, at low level, sst5 [53, 150], while, in TSH-secreting tumors, sst2 is mainly coexpressed with sst3 and sst5 [151].

More recently, a splice variant of sst5, hsst5TMD4, forming a truncated receptor, was identified in several human pituitary tumors and, importantly, in GH-secreting tumors in which its expression was negatively correlated to clinical responsiveness to octreotide $[7,152]$.

In $\mathrm{GH}$ secreting adenomas, octreotide and lanreotide, mainly acting on sst 2 and slightly less effectively on sst5, inhibit GH secretion [153], normalize IGF-1 serum levels, and cause tumor size reduction [154]. These analogs are the standard therapy for acromegalic patients, however the functional interactions between sst 2 and 5 provide the rationale for studies using pasireotide (displaying a binding affinity sst5>sst2) [73].

Interestingly, the direct antiproliferative effects of SST analogs in pituitary adenoma cells are dissociated from the antisecretory effects, as shown by the differential responses to selective analogs $[155,156]$. Inhibition of pituitary adenoma cell proliferation in response to native SST or lanreotide is mediated by increased PTP activity, as observed in primary cell cultures of human GH-secreting or nonfunctioning pituitary adenomas [157, 158]. Moreover, octreotide activation of SHP1 leading to tumor cell growth arrest through the regulation of the tumor suppressor Zacl, has been described in GH3 pituitary adenoma cells [110]. Finally, sst2 activation may also lead to caspase-mediated proapoptotic effects in somatotroph tumor cells treated with octreotide, via a PTPdependent pathway [136], although the specific enzyme was not identified.

Prolactin-secreting adenomas which mainly express sst1 and sst5, often associated with $\mathrm{D} 2 \mathrm{R}$, show low sensitivity to somatostatinergic treatment that scarcely reduces prolactin secretion [149]. A study on primary prolactinoma cells overexpressing sst2 showed that the chimeric compound BIM-23A760 does not improve prolactin release suppression as compared to cabergoline, suggesting the predominance of dopaminergic signaling in prolactin release [159]. Thus, dopamine receptor agonists remain the most effective medical therapy for these tumors; however, a low percentage of patients did not respond to these drugs, probably because an overexpression of sst2, could represent a target for SST analogs.

ACTH-secreting tumor markedly express sst5 and D2R, and to a lesser extent sst1, 2 and 3 [160], but their pathobiology is more complex since, beside the corticotroph tumor, $70 \%$ of patients bear Cushing's disease showing circulating cortisol excess that can downregulate ACTH-cell sst2 expression leading to the lack of response to sst2 selective drugs, octreotide and lanreotide [74]. Pasireotide, acting on sst5, the most expressed receptor involved in ACTH secretion, may overcome the dependence of sst 2 expression from high cortisol levels [161]. In fact, in vitro studies [162] showed that pasireotide significantly inhibited ACTH secretion from primary cultures of human ACTH-secreting pituitary adenomas, while clinical studies have shown that pasireotide can reduce urinary free cortisol levels in patients with Cushing's disease [163]. In this light, pasireotide was recently approved for the medical treatment of ACTH-secreting pituitary adenomas [76].

TSH-secreting tumors are extremely rare adenomas, highly expressing sst1, 2 and 5, in which sst2 plays a key role in the control of TSH secretion. Pharmacological therapy for TSH-secreting pituitary adenomas with sst2-preferring analogs, octreotide and lanreotide, induces normalization of hormone levels in the great majority of patients and tumor shrinkage in almost half of them [164]. However, besides sst 2 expression the ratio sst5/sst 2 and combined sst and D2R targeting was recently demonstrated to have a predictive value to long-term treatment with SST analogs and improve the response rate in octreotide-resistant tumors $[165,166]$.

GEP-NETs display high expression of SST receptors (higher for sst2 and sst5, lower for sst1, 3, and 4) [167], and thus SST analogs are potentially useful for the diagnosis and therapy of these tumors $[44,168]$. A prospective study on the effect of octreotide LAR showed its efficacy in prolonging median time to tumor progression and increase the percentage of stable disease in patients with metastatic midgut NETs [169]. Currently, trials with lanreotide versus placebo in nonfunctioning pancreatic NET patients and pasireotide long-acting release in patients with metastatic NET are ongoing. Moreover, a promising therapeutic strategy recently proposed is the combination of octreotide or pasireotide and everolimus, an inhibitor of the protein kinase mammalian target of rapamycin (mTOR) controlling cell proliferation and survival [170]. Similar data were also reported in primary cultures of human nonfunctioning pituitary adenomas, in which the treatment with octreotide highly sensitized the cells to another mTOR inhibitor, rapamycin [116], thus supporting the possibility to increase SST efficacy by combining SST receptor agonists with other signal transduction inhibitors.

\section{Somatostatin and Somatostatin Receptors in Non-Endocrine Tumors}

Cytotoxic drugs still represent the main pharmacological approach for treatment of solid cancer although the induction of drug resistance, high toxicity, and poor selectivity often prevent successful outcome. However, novel promising therapeutic strategies such as targeted and biological therapy are aimed to reduce toxicity and improve selectivity. Among receptors for many regulatory peptides, SST receptors expressed on the membrane of tumor cells have provided 
the rationale for the development of SST agonists able to selectively target tumor cells. In fact, beside SST analogs, as previously described, cytotoxic SST derivatives (cytotoxic molecules conjugated to SST or analog backbone), and radiolabeled SST analogs for intracellular radiotherapy have been developed [171]. Some of these compounds are currently in preclinical and clinical trials, other have already reached a well-established clinical application. Here a concise view is given of SST receptor expression and SST analogs tested and used as antineoplastic agents, to the intensive research which is conducted in this field.

8.1. Prostate Cancer. All of the five SST receptors are detectable in prostate cancer tissues, with sstl the most expressed, followed by sst5 and sst $2[172,173]$. Many studies using SST analogs (octreotide, lanreotide, pasireotide) have been performed in prostate cancer cell lines [174, 175] highlighting both antiproliferative and proapoptotic effects. In LNCaP cells, an interaction between SST receptors and D2R was also documented. These cells constitutively express sst1, 2 and 5 and D2R, and their activation by receptor selective SST agonists or SST/dopamine chimeras, that synergistically activates sst2/D2R dimers, significantly inhibited cell proliferation [55]. Similarly, the use of SST analogs conjugated with doxorubicin (AN-162) showed a powerful in vitro and in vivo efficacy in experimental prostate cancer model, being also able to affect metastasization [176]. However, clinical studies using octreotide and lanreotide as single agents for the treatment of prostate cancer patients did not show significant results [177], while combination therapies, including octreotide LAR plus dexamethasone and the bisphosphonate zoledronic acid produced objective responses and symptomatic improvement in androgen ablation-refractory patients $[178,179]$.

8.2. Breast Cancer. Breast tumors express all SST receptors at high level, sst2 being the predominant subtype [180]. Experimental studies support the efficacy of octreotide and lanreotide in the control of tumor growth in vitro and in xenograft models [181-183]. Recently, the truncated sst5 variant, sst5TMD4, related to the abnormal responses to SST analogs in pituitary tumors has been identified in poorly differentiated human breast cancers, where it correlates and interacts with sst 2 altering its signaling and affecting tumor pathophysiology, while it is absent in normal mammary gland [184].

IGF-1 levels are associated with breast hyperplasia and cancer risk [185]. IGF-1 effects might be blocked by SST analogs though an indirect regulation mediated by the inhibition of GH release. In vivo studies reported that pasireotide could affect IGF-1 activity as far as cell division and inhibition of apoptosis, but coadministration of tamoxifen did not result in greater effects $[186,187]$. In a rat model of breast hyperplasia [188] this effect was prevented by pasireotide and tamoxifen coadministration, while octreotide was less effective, while in another study the SST analog shows the same activity as tamoxifen in preventing GH- and estrogeninduced mammary hyperplasia [188].
Controversial results were obtained in breast cancer patients treated with SST analogs. In a phase II study, lanreotide + tamoxifen induced a $50 \%$ of overall objective response rate, with a $12.5 \%$ of complete responses, and similar responses were observed using the octreotide/tamoxifen association [189, 190]. However, while a subsequent metaanalysis seemed to confirm these results when SST analogs were given as first-line therapy [191], several phase III studies did not show any clinical improvement by the addition of octreotide LAR to tamoxifen [192-194], even in cases in which changes in circulating IGF-1 and C-peptide levels were statistically significant [195].

8.3. Cancers of the Gastrointestinal Tract. Cancers of the digestive tract differently express SST receptors according to the localization [196]. In particular, colorectal malignancies predominantly express sst1 (65\%) followed by sst5 (39\%) and sst2 (36\%) [197], hepatocellular carcinomas express mainly sst5, although sst1, 2, and 3 are also often detected (about 40-60\%) [198], while in gastric carcinomas sst2 and 5 are very commonly expressed, although sst 3 is detected in several cases [199]. Moreover, also gastrointestinal stromal tumors (GIST) were reported to express all five SST receptors in variable percentages [200, 201].

Antiproliferative activity of SST and analogs mediated by sst 3 and 5 was demonstrated in vitro in different colon cancer cell lines through a PTP-dependent inhibition of COX2 expression and activity [202]. When translated to the clinical studies in patients with advanced colorectal cancer controversial results were obtained. In a randomized study in 46 nonresponder patients to conventional chemotherapy the administration of octreotide significantly increased overall survival in comparison with patients receiving supportive care (24 versus 12 weeks), but no different effects than placebo were observed in a larger phase III trial in asymptomatic colon cancer patients $[203,204]$.

As far as hepatocellular cancer, proliferation was reduced by octreotide in human cell lines, [205] and by pasireotide that synergized with celecoxib to induce apoptosis in vitro and to prolong the survival of nude mice bearing hepatocarcinoma xenografts [206].

A phase II clinical trial using octreotide LAR in combination with sorafenib showed partial responses or disease stability in about $75 \%$ of the patients [207], but these results were not confirmed in a phase III trial, in which octreotide LAR was compared to placebo [208].

Hypermethylation of SST promoter was identified as potential mechanism of gastric cancer development [209], clearly highlighting the potential role for SST receptors in gastric cell proliferation. Octreotide reduced gastric carcinoma cell line proliferation in vitro interfering with Akt and telomerase activity [210], an effect that was dependent on the expression of sst3. The COX2 inhibitor rofecoxib, administered with octreotide in a gastric cancer xenograft model, caused an almost total tumor growth suppression due to induction of apoptosis [211]. These in vitro results were confirmed in clinical studies in which octreotide potentiated celecoxib effect in gastric carcinoma patients, increasing both 
necrosis and apoptosis and inhibiting angiogenesis [212]. Antivasculogenesis effects of SST gastric cancer patients were ascribed to a direct downregulation of both VEGF and its receptor VEGFR3 activity induced by the peptide in an openlabel, randomized trial including 60 patients [213].

Above evidence suggests that SST and its analogs can be potentially useful as adjuvant therapy to improve the outcome of some neoplasms of the digestive tracts, although the large discrepancies between experimental and clinical studies clearly suggest that the exact comprehension of the mechanisms responsible of the antiproliferative effects mediated by SST receptors will require further studies.

8.4. Brain Tumors. Glioblastoma multiforme (GBM), the most aggressive primary brain cancer, expresses multiple SST receptors [214], being sst1 and sst 2 the most frequent in both glioma tissues and cell lines $[133,215]$. In vitro, the activation of SST receptors leads to antiproliferative and anti-invasive effects $[133,216]$. Besides the expression of SST receptors, in both GBM cell lines and primary cell cultures specific signaling pathways regulated upon SST receptors activation were identified as determinants of the transduction of the growthinhibitory effects of SST, showing a prominent role for the activation of PTP $\eta[133,134]$. Subtype-selective agonists for each of SST receptors provide a direct approach to define individual role of SST receptors in the antiproliferative effects of SST [69]. Using C6 rat glioma cells, an experimental model that in vivo closely reflects invasion and neovascularization of human GBM growth [217], the efficacy of SST analogs was assayed on tumor growth in nude mice [70]. Single agonists of sst1, 2, and 5 affected both tumor growth and neoangiogenesis via the inactivation of ERK1/2 and the upregulation of $\mathrm{p} 27^{\mathrm{Kip} 1}$, representing a common intracellular pathway for all the receptors. Interestingly, while the sst5 agonist (BIM23206) was maximally effective on tumor development, sstl and sst 2 selective agonists (BIM-23745 and BIM-23210) were more efficacious on tumor vascularization [70]. Thus, it was hypothesized that the simultaneous activation of different SST receptor subtypes will improve the potential of this antitumor therapeutic approach [218].

Besides GBM, another common primary intracranial neoplasia is meningioma that despite a general low aggressive clinical behavior, includes, in few cases, high-grade lesions that recur after surgery and radiotherapy. The high incidence of SST receptors in human meningiomas is known since decades [219] and the inhibitory role of SST in the control of proliferation in primary cultures of human meningioma cells has been described [220]. The rationale for the use of SST analogs in the control of intracranial meningioma is supported by the widespread expression of SST receptors in this tumor and by the fact that currently no adjuvant therapy for meningioma is available in patients with unresectable or radioresistant lesions [221]. Limited clinical data are currently available about SST analogs in vivo, but SST antiangiogenic activity might be useful in refractory meningiomas as reported by The Central Nervous System National Comprehensive Cancer Network guidelines that suggests as treatment options hydroxyurea, interferon- $\alpha$, or octreotide
LAR [222]. In addition, a phase II trial for recurrent or progressive patients treated with pasireotide is ongoing.

The antitumor effects described above are to be considered as examples and not exhaustive of all tumors expressing SST receptors in which preclinical and clinical investigations have been performed with SST analogs. However, the main relevant results reviewed can highlight the intriguing option to add SST analogs to cytotoxic or targeted drugs to improve the clinical outcome of various endocrine and nonneuroendocrine neoplasms.

\section{Conclusions}

SST receptors represent a potential relevant drug target for the treatment of several tumor histotypes. In fact, starting from the identification of the expression, and in some cases overexpression, of these receptors in several human tumors, several clinical trials were performed to assess the possible clinical efficacy of SST agonists in almost all tumor types. However, to date contrasting or clearly negative results were obtained, with the only significant exceptions of pituitary adenomas and, possibly, GEP-NETs. In fact, in these tumors, a significant inhibition of hormone secretion (responsible of most clinical symptoms) and, although less evident in all the tumors, cell cycle arrest was documented. However, in recent years a significant advancement in understanding the biology of SST receptors (mainly the mechanisms of dimerization and cellular trafficking) and the identification of PTPs as main mediators of the antiproliferative effects may help in the comprehension for the reason in the so far disappointing results for most of the tumor treated. In particular, data on the balance of SST receptor subtype expression [166] and the expression of specific PTPs [129] may help in the identification of subset of tumors most likely to be responsive to SST analogs treatment, thus providing a step ahead in the personalized treatment of patients in oncology. Finally, the recent development of SST-based PRRT could represent an adjunctive approach to treat in other ways non-responder tumors.

\section{Acknowledgment}

The support of the Italian Association for Cancer Research is gratefully acknowledged.

\section{References}

[1] Y. C. Patel, "Somatostatin and its receptor family," Frontiers in Neuroendocrinology, vol. 20, no. 3, pp. 157-198, 1999.

[2] J. Epelbaum, J. L. Guillou, F. Gastambide, D. Hoyer, E. Duron, and C. Viollet, "Somatostatin, Alzheimer's disease and cognition: an old story coming of age?" Progress in Neurobiology, vol. 89, no. 2, pp. 153-161, 2009.

[3] G. Kharmate, P. S. Rajput, H. L. Watt et al., "Role of somatostatin receptor 1 and 5 on epidermal growth factor receptor mediated signaling," Biochimica et Biophysica Acta, vol. 1813, no. 6, pp. 1172-1189, 2011.

[4] U. Kumar, "Cross-talk and modulation of signaling between somatostatin and growth factor receptors," Endocrine, vol. 40, no. 2, pp. 168-180, 2011. 
[5] T. Florio and G. Schettini, "Multiple intracellular effecters modulate physiological functions of the cloned somatostatin receptors," Journal of Molecular Endocrinology, vol. 17, no. 2, pp. 89-100, 1996.

[6] J. Córdoba-Chacón, M. D. Gahete, J. P. Castaño, R. D. Kineman, and R. M. Luque, "Somatostatin and its receptors contribute in a tissue-specific manner to the sex-dependent metabolic (fed/fasting) control of growth hormone axis in mice," American Journal of Physiology, vol. 300, no. 1, pp. E46-E54, 2011.

[7] M. Durán-Prado, M. D. Gahete, A. J. Martínez-Fuentes et al., "Identification and characterization of two novel truncated but functional isoforms of the somatostatin receptor subtype 5 differentially present in pituitary tumors," The Journal of Clinical Endocrinology and Metabolism, vol. 94, no. 7, pp. 2634-2643, 2009.

[8] G. Weckbecker, I. Lewis, R. Albert et al., "Opportunities in somatostatin research: biological, chemical and therapeutic aspects," Nature Reviews Drug Discovery, vol. 2, no. 12, pp. 9991017, 2003.

[9] L. de Lecea, P. Ruiz-Lozano, P. E. Danielson et al., "Cloning, mRNA expression, and chromosomal mapping of mouse and human preprocortistatin," Genomics, vol. 42, no. 3, pp. 499-506, 1997.

[10] J. P. Castaño, E. Ghigo, R. D. Kineman, L. de Lecea, M. M. Malagón, and H. Vaudry, "Somatostatin, cortistatin and their receptors in health and disease. Foreword," Molecular and Cellular Endocrinology, vol. 286, no. 1-2, pp. 1-2, 2008.

[11] L. de Lecea, "Cortistatin-functions in the central nervous system," Molecular and Cellular Endocrinology, vol. 286, no. 12, pp. 88-95, 2008.

[12] N. Robas, E. Mead, and M. Fidock, "MrgX2 is a high potency cortistatin receptor expressed in dorsal root ganglion," The Journal of Biological Chemistry, vol. 278, no. 45, pp. 4440044404, 2003.

[13] S. Siehler, C. Nunn, J. Hannon, D. Feuerbach, and D. Hoyer, "Pharmacological profile of somatostatin and cortistatin receptors," Molecular and Cellular Endocrinology, vol. 286, no. 1-2, pp. 26-34, 2008.

[14] J. Guillermet-Guibert, H. Lahlou, P. Cordelier, C. Bousquet, S. Pyronnet, and C. Susini, "Physiology of somatostatin receptors," Journal of Endocrinological Investigation, vol. 28, supplement 11, pp. 5-9, 2005.

[15] T. Florio, S. Thellung, and G. Schettini, "Intracellular transducing mechanisms coupled to brain somatostatin receptors," Pharmacological Research, vol. 33, no. 6, pp. 297-305, 1996.

[16] A. Vasilaki, D. Papasava, D. Hoyer, and K. Thermos, "The somatostatin receptor $\left(\mathrm{sst}_{1}\right)$ modulates the release of somatostatin in the nucleus accumbens of the rat," Neuropharmacology, vol. 47, no. 4, pp. 612-618, 2004.

[17] G. Schettini, T. Florio, G. Magri et al., "Somatostatin and SMS 201-995 reverse the impairment of cognitive functions induced by cysteamine depletion of brain somatostatin," European Journal of Pharmacology, vol. 151, no. 3, pp. 399-407, 1988.

[18] L. Vecsei and E. Widerlov, "Effects of intracerebroventricularly administered somatostatin on passive avoidance, shuttle-box behaviour and open-field activity in rats," Neuropeptides, vol. 12, no. 4, pp. 237-242, 1988.

[19] T. Florio, C. Ventra, A. Postiglione, and G. Schettini, "Agerelated alterations of somatostatin gene expression in different rat brain areas," Brain Research, vol. 557, no. 1-2, pp. 64-68, 1991.

[20] M. Grimaldi, T. Florio, and G. Schettini, "Somatostatin inhibits interleukin 6 release from rat cortical type I astrocytes via the inhibition of adenylyl cyclase," Biochemical and Biophysical Research Communications, vol. 235, no. 1, pp. 242-248, 1997.
[21] E. Pintér, Z. Helyes, and J. Szolcsanyi, "Inhibitory effect of somatostatin on inflammation and nociception," Pharmacology and Therapeutics, vol. 112, no. 2, pp. 440-456, 2006.

[22] D. Ferone, P. M. van Hagen, R. Pivonello, A. Colao, S. W. J. Lamberts, and L. J. Hofland, "Physiological and pathophysiological role of somatostatin receptors in the human thymus," European Journal of Endocrinology, vol. 143, supplement 1, pp. S27-S34, 2000.

[23] D. Ferone, M. Boschetti, E. Resmini et al., "Neuroendocrineimmune interactions: the role of cortistatin/somatostatin system," Annals of the New York Academy of Sciences, vol. 1069, pp. 129-144, 2006.

[24] P. Ameri and D. Ferone, "Diffuse endocrine system, neuroendocrine tumors and immunity: what's new?" Neuroendocrinology, vol. 95, no. 4, pp. 267-276, 2012.

[25] V. D. Corleto, "Somatostatin and the gastrointestinal tract," Current Opinion in Endocrinology, Diabetes and Obesity, vol. 17, no. 1, pp. 63-68, 2010.

[26] A. Ben-Shlomo and S. M. Shlomo, "Pituitary somatostatin receptor signaling," Trends in Endocrinology and Metabolism, vol. 21, no. 3, pp. 123-133, 2010.

[27] T. Florio, C. Rim, R. E. Hershberger, M. Loda, and P. J. S. Stork, "The somatostatin receptor SSTR1 is coupled to phosphotyrosine phosphatase activity in CHO-K1 cells," Molecular Endocrinology, vol. 8, no. 10, pp. 1289-1297, 1994.

[28] T. Florio, S. Thellung, S. Arena et al., "Somatostatin receptor 1 (SSTR1)-mediated inhibition of cell proliferation correlates with the activation of the MAP kinase cascade: role of the phosphotyrosine phosphatase SHP-2," Journal of Physiology Paris, vol. 94, no. 3-4, pp. 239-250, 2000.

[29] R. E. Hershberger, B. L. Newman, T. Florio et al., "The somatostatin receptors SSTR1 and SSTR2 are coupled to inhibition of adenylyl cyclase in Chinese hamster ovary cells via pertussis toxin-sensitive pathways," Endocrinology, vol. 134, no. 3, pp. 1277-1285, 1994.

[30] O. Meucci, E. Landolfi, A. Scorziello et al., "Dopamine and somatostatin inhibition of prolactin secretion from MMQ pituitary cells: role of adenosine triphosphate-sensitive potassium channels," Endocrinology, vol. 131, no. 4, pp. 1942-1947, 1992.

[31] G. Schettini, T. Florio, O. Meucci et al., "Somatostatin inhibition of adenylate cyclase activity in different brain areas," Brain Research, vol. 492, no. 1-2, pp. 65-71, 1989.

[32] G. Schettini, T. Florio, O. Meucci, E. Landolfi, G. Lombardi, and A. Marino, "Somatostatin inhibition of anterior pituitary adenylate cyclase activity: different sensitivity between male and female rats," Brain Research, vol. 439, no. 1-2, pp. 322-329, 1988.

[33] T. Florio, H. Yao, K. D. Carey, T. J. Dillon, and P. J. S. Stork, "Somatostatin activation of mitogen-activated protein kinase via somatostatin receptor 1 (SSTR1)," Molecular Endocrinology, vol. 13, no. 1, pp. 24-37, 1999.

[34] F. Viana and B. Hille, "Modulation of high voltage-activated calcium channels by somatostatin in acutely isolated rat amygdaloid neurons," The Journal of Neuroscience, vol. 16, no. 19, pp. 6000-6011, 1996.

[35] H. J. Kreienkamp, H. H. Hönck, and D. Richter, "Coupling of rat somatostatin receptor subtypes to a G-protein gated inwardly rectifying potassium channel (GIRK1)," FEBS Letters, vol. 419, no. 1, pp. 92-94, 1997.

[36] L. Buscail, N. Delesque, J. P. Esteve et al., "Stimulation of tyrosine phosphatase and inhibition of cell proliferation by somatostatin analogues: mediation by human somatostatin receptor subtypes SSTR1 and SSTR2," Proceedings of the National Academy of Sciences of the United States of America, vol. 91, no. 6, pp. 2315-2319, 1994. 
[37] L. Buscail, J. P. Estève, N. Saint-Laurent et al., "Inhibition of cell proliferation by the somatostatin analogue RC-160 is mediated by somatostatin receptor subtypes SSTR2 and SSTR5 through different mechanisms," Proceedings of the National Academy of Sciences of the United States of America, vol. 92, no. 5, pp. 15801584, 1995.

[38] T. Florio, A. Scorziello, M. Fattore et al., "Somatostatin inhibits PC $\mathrm{C} 13$ thyroid cell proliferation through the modulation of phosphotyrosine phosphatase activity: impairment of the somatostatinergic effects by stable expression of eia viral oncogene," The Journal of Biological Chemistry, vol. 271, no. 11, pp. 6129-6136, 1996.

[39] S. Seino, "Somatostatin receptor subtype SSTR2 mediates the inhibition of high-voltage-activated calcium channels by somatostatin and its analogue SMS 201-995," FEBS Letters, vol. 355, no. 2, pp. 117-120, 1994.

[40] D. B. Reardon, P. Dent, S. L. Wood, T. Kong, and T. W. Sturgill, "Activation in vitro of somatostatin receptor subtypes 2, 3, or 4 stimulates protein tyrosine phosphatase activity in membranes from transfected Ras-transformed nih 3T3 cells: coexpression with catalytically inactive SHP-2 blocks responsiveness," Molecular Endocrinology, vol. 11, no. 8, pp. 1062-1069, 1997.

[41] D. Roosterman, G. Glassmeier, H. Baumeister, H. Scherübl, and W. Meyerhof, "A somatostatin receptor 1 selective ligand inhibits $\mathrm{Ca}^{2+}$ currents in rat insulinoma 1046-38 cells," FEBS Letters, vol. 425, no. 1, pp. 137-140, 1998.

[42] R. E. White, A. Schonbrunn, and D. L. Armstrong, "Somatostatin stimulates $\mathrm{Ca}^{2+}$-activated $\mathrm{K}^{+}$channels through protein dephosphorylation," Nature, vol. 351, no. 6327, pp. 570-573, 1991.

[43] H. Yoshitomi, Y. Fujii, M. Miyazaki, N. Nakajima, N. Inagaki, and S. Seino, "Involvement of MAP kinase and c-fos signaling in the inhibition of cell growth by somatostatin," American Journal of Physiology, vol. 272, no. 5, pp. E769-E774, 1997.

[44] T. Florio, "Molecular mechanisms of the antiproliferative activity of somatostatin receptors (SSTRs) in neuroendocrine tumors," Frontiers in Bioscience, vol. 13, no. 3, pp. 822-840, 2008.

[45] L. N. Møller, C. E. Stidsen, B. Hartmann, and J. J. Holst, "Somatostatin receptors," Biochimica et Biophysica Acta, vol. 1616, no. 1, pp. 1-84, 2003.

[46] M. Durán-Prado, M. M. Malagón, F. Gracia-Navarro, and J. P. Castaño, "Dimerization of G protein-coupled receptors: new avenues for somatostatin receptor signalling, control and functioning," Molecular and Cellular Endocrinology, vol. 286, no. 1-2, pp. 63-68, 2008.

[47] M. Rocheville, D. C. Lange, U. Kumar, R. Sasi, R. C. Patel, and Y. C. Patel, "Subtypes of the somatostatin receptor assemble as functional homo- and heterodimers," The Journal of Biological Chemistry, vol. 275, no. 11, pp. 7862-7869, 2000.

[48] A. Baragli, H. Alturaihi, H. L. Watt, A. Abdallah, and U. Kumar, "Heterooligomerization of human dopamine receptor 2 and somatostatin receptor 2. Co-immunoprecipitation and fluorescence resonance energy transfer analysis," Cellular Signalling, vol. 19, no. 11, pp. 2304-2316, 2007.

[49] M. Rocheville, D. C. Lange, U. Kumar, S. C. Patel, R. C. Patel, and Y. C. Patel, "Receptors for dopamine and somatostatin: formation of hetero-oligomers with enhanced functional activity," Science, vol. 288, no. 5463, pp. 154-157, 2000.

[50] M. Grant, H. Alturaihi, P. Jaquet, B. Collier, and U. Kumar, "Cell growth inhibition and functioning of human somatostatin receptor type 2 are modulated by receptor heterodimerization," Molecular Endocrinology, vol. 22, no. 10, pp. 2278-2292, 2008.

[51] M. Grant, R. C. Patel, and U. Kumar, "The role of subtypespecific ligand binding and the C-tail domain in dimer formation of human somatostatin receptors," The Journal of Biological Chemistry, vol. 279, no. 37, pp. 38636-38643, 2004.
[52] S. A. War, R. K. Somvanshi, and U. Kumar, "Somatostatin receptor-3 mediated intracellular signaling and apoptosis is regulated by its cytoplasmic terminal," Biochimica et Biophysica Acta, vol. 1813, no. 3, pp. 390-402, 2011.

[53] T. Florio, F. Barbieri, R. Spaziante et al., "Efficacy of a dopaminesomatostatin chimeric molecule, BIM-23A760, in the control of cell growth from primary cultures of human non-functioning pituitary adenomas: a multi-center study," Endocrine-Related Cancer, vol. 15, no. 2, pp. 583-596, 2008.

[54] L. J. Hofland, R. A. Feelders, W. W. de Herder, and S. W. J. Lamberts, "Pituitary tumours: the sst/D2 receptors as molecular targets," Molecular and Cellular Endocrinology, vol. 326, no. 1-2, pp. 89-98, 2010.

[55] M. Arvigo, F. Gatto, M. Ruscica et al., "Somatostatin and dopamine receptor interaction in prostate and lung cancer cell lines," Journal of Endocrinology, vol. 207, no. 3, pp. 309-317, 2010.

[56] H. L. Watt, G. D. Kharmate, and U. Kumar, "Somatostatin receptors 1 and 5 heterodimerize with epidermal growth factor receptor: agonist-dependent modulation of the downstream MAPK signalling pathway in breast cancer cells," Cellular Signalling, vol. 21, no. 3, pp. 428-439, 2009.

[57] M. G. Pan, T. Florio, and P. J. S. Stork, "G protein activation of a hormone-stimulated phosphatase in human tumor cells," Science, vol. 256, no. 5060, pp. 1215-1217, 1992.

[58] Z. Csaba, S. Peineau, and P. Dournaud, "Molecular mechanisms of somatostatin receptor trafficking," Journal of Molecular Endocrinology, vol. 48, no. 1, pp. R1-R12, 2012.

[59] G. Tulipano, R. Stumm, M. Pfeiffer, H. J. Kreienkamp, V. Höllt, and S. Schulz, "Differential $\beta$-arrestin trafficking and endosomal sorting of somatostatin receptor subtypes," The Journal of Biological Chemistry, vol. 279, no. 20, pp. 21374-21382, 2004.

[60] G. Tulipano and S. Schulz, "Novel insights in somatostatin receptor physiology," European Journal of Endocrinology, vol. 156, supplement 1, pp. S3-S11, 2007.

[61] S. Jacobs and S. Schulz, "Intracellular trafficking of somatostatin receptors," Molecular and Cellular Endocrinology, vol. 286, no. 12, pp. 58-62, 2008.

[62] J. C. Reubi, B. Waser, R. Cescato, B. Gloor, C. Stettler, and E. Christ, "Internalized somatostatin receptor subtype 2 in neuroendocrine tumors of octreotide-treated patients," The Journal of Clinical Endocrinology and Metabolism, vol. 95, no. 5, pp. 2343-2350, 2010.

[63] S. Lesche, D. Lehmann, F. Nagel, H. A. Schmid, and S. Schulz, "Differential effects of octreotide and pasireotide on somatostatin receptor internalization and trafficking in vitro," The Journal of Clinical Endocrinology and Metabolism, vol. 94, no. 2, pp. 654-661, 2009.

[64] B. Waser, R. Cescato, M. L. Tamma, H. R. Maecke, and J. C. Reubi, "Absence of somatostatin $\mathrm{SST}_{2}$ receptor internalization in vivo after intravenous SOM230 application in the AR42J animal tumor model," European Journal of Pharmacology, vol. 644, no. 1-3, pp. 257-262, 2010.

[65] A. Kliewer, A. Mann, A. Petrich et al., "A transplantable phosphorylation probe for direct assessment of $G$ proteincoupled receptor activation," PloS ONE, vol. 7, no. 6, Article ID e39458, 2012.

[66] R. Cozzi and R. Attanasio, "Octreotide long-acting repeatable for acromegaly," Expert Review of Clinical Pharmacology, vol. 5, no. 2, pp. 125-143, 2012.

[67] G. Mazziotti and A. Giustina, "Effects of lanreotide SR and Autogel on tumor mass in patients with acromegaly: a systematic review," Pituitary, vol. 13, no. 1, pp. 60-67, 2010. 
[68] S. P. Rohrer, E. T. Birzin, R. T. Mosley et al., "Rapid identification of subtype-selective agonists of the somatostatin receptor through combinatorial chemistry," Science, vol. 282, no. 5389, pp. 737-740, 1998.

[69] F. Barbieri, A. Pattarozzi, M. Gatti et al., "Somatostatin receptors 1,2 , and 5 cooperate in the somatostatin inhibition of C6 glioma cell proliferation in vitro via a phosphotyrosine phosphatase$\eta$-dependent inhibition of extracellularly regulated kinase-1/2," Endocrinology, vol. 149, no. 9, pp. 4736-4746, 2008.

[70] F. Barbieri, A. Pattarozzi, M. Gatti et al., "Differential efficacy of SSTR1, -2, and -5 agonists in the inhibition of C6 glioma growth in nude mice," American Journal of Physiology, vol. 297, no. 5, pp. E1078-E1088, 2009.

[71] D. Cervia, D. Langenegger, E. Schuepbach et al., "Binding and functional properties of the novel somatostatin analogue KE 108 at native mouse somatostatin receptors," Neuropharmacology, vol. 48, no. 6, pp. 881-893, 2005.

[72] U. Plockinger, U. Hoffmann, M. Geese et al., "DG3173 (somatoprim), a unique somatostatin receptor subtypes 2-, 4- and 5selective analogue, effectively reduces GH secretion in human GH-secreting pituitary adenomas even in octreotide nonresponsive tumours," European Journal of Endocrinology, vol. 166, no. 2, pp. 223-234, 2012.

[73] H. A. Schmid, "Pasireotide (SOM230): development, mechanism of action and potential applications," Molecular and Cellular Endocrinology, vol. 286, no. 1-2, pp. 69-74, 2008.

[74] A. Ben-Shlomo, H. Schmid, K. Wawrowsky et al., "Differential ligand-mediated pituitary somatostatin receptor subtype signaling: implications for corticotroph tumor therapy," The Journal of Clinical Endocrinology and Metabolism, vol. 94, no. 11, pp. 4342-4350, 2009.

[75] A. Ben-Shlomo and S. Melmed, "Pasireotide-a somatostatin analog for the potential treatment of acromegaly, neuroendocrine tumors and Cushing's disease," IDrugs, vol. 10, no. 12, pp. 885-895, 2007.

[76] A. Colao, S. Petersenn, J. Newell-Price et al., "A 12-month phase 3 study of pasireotide in Cushing's disease," The New England Journal of Medicine, vol. 366, no. 10, pp. 914-924, 2012.

[77] A. Saveanu, G. Gunz, S. Guillen, H. Dufour, M. D. Culler, and P. Jaquet, "Somatostatin and dopamine-somatostatin multiple ligands directed towards somatostatin and dopamine receptors in pituitary adenomas," Neuroendocrinology, vol. 83, no. 3-4, pp. 258-263, 2006

[78] I. Shimon, T. Rubinek, M. Hadani, and N. Alhadef, "PTR-3173 (Somatoprim), a novel somatostatin analog with affinity for somatostatin receptors 2,4 and 5 is a potent inhibitor of human GH secretion," Journal of Endocrinological Investigation, vol. 27, no. 8, pp. 721-727, 2004.

[79] K. Elekes, Z. Helyes, L. Kereskai et al., "Inhibitory effects of synthetic somatostatin receptor subtype 4 agonists on acute and chronic airway inflammation and hyperreactivity in the mouse," European Journal of Pharmacology, vol. 578, no. 2-3, pp. 313-322, 2008.

[80] O. Szokolóczi, R. Schwab, I. Peták et al., “TT232, a novel signal transduction inhibitory compound in the therapy of cancer and inflammatory diseases," Journal of Receptors and Signal Transduction, vol. 25, no. 4-6, pp. 217-235, 2005.

[81] J. Szolcsanyi, K. Bölcskei, A. Szabó et al., "Analgesic effect of TT-232, a heptapeptide somatostatin analogue, in acute pain models of the rat and the mouse and in streptozotocininduced diabetic mechanical allodynia," European Journal of Pharmacology, vol. 498, no. 1-3, pp. 103-109, 2004.

[82] R. Ramón, P. Martín-Gago, X. Verdaguer et al., "SSTR1- and SSTR3-selective somatostatin analogues," ChemBioChem, vol. 12, no. 4, pp. 625-632, 2011.
[83] L. Poitout, P. Roubert, M. O. Contour-Galcéra et al., "Identification of potent non-peptide somatostatin antagonists with sst selectivity," Journal of Medicinal Chemistry, vol. 44, no. 18, pp. 2990-3000, 2001.

[84] F. Gatto and L. J. Hofland, "The role of somatostatin and dopamine D2 receptors in endocrine tumors," EndocrineRelated Cancer, vol. 18, no. 6, pp. R233-R251, 2011.

[85] A. Saveanu, E. Lavaque, G. Gunz et al., "Demonstration of enhanced potency of a chimeric somatostatin-dopamine molecule, BIM-23A387, in suppressing growth hormone and prolactin secretion from human pituitary somatotroph adenoma cells," The Journal of Clinical Endocrinology and Metabolism, vol. 87, no. 12, pp. 5545-5552, 2002.

[86] D. Ferone, M. Arvigo, C. Semino et al., "Somatostatin and dopamine receptor expression in lung carcinoma cells and effects of chimeric somatostatin-dopamine molecules on cell proliferation," American Journal of Physiology, vol. 289, no. 6, pp. E1044-E1050, 2005.

[87] M. D. Culler, "Somatostatin-dopamine chimeras: a novel approach to treatment of neuroendocrine tumors," Hormone and Metabolic Research, vol. 43, no. 12, pp. 854-857, 2011.

[88] S. W. J. Lamberts, W. H. Bakker, J. C. Reubi, and E. P. Krenning, "Somatostatin-receptor imaging in the localization of endocrine tumors," The New England Journal of Medicine, vol. 323, no. 18, pp. 1246-1249, 1990.

[89] I. M. Modlin, S. F. Moss, K. Oberg et al., "Gastrointestinal neuroendocrine (carcinoid) tumours: current diagnosis and management," Medical Journal of Australia, vol. 193, no. 1, pp. 46-52, 2010.

[90] D. J. Kwekkeboom, B. L. Kam, M. Van Essen et al., "Somatostatin receptor-based imaging and therapy of gastroenteropancreatic neuroendocrine tumors," Endocrine-Related Cancer, vol. 17, no. 1, pp. R53-R73, 2010.

[91] I. Buchmann, M. Henze, S. Engelbrecht et al., "Comparison of ${ }^{68} \mathrm{Ga}$-DOTATOC PET and ${ }^{111}$ In-DTPAOC (Octreoscan) SPECT in patients with neuroendocrine tumours," European Journal of Nuclear Medicine and Molecular Imaging, vol. 34, no. 10, pp. 1617-1626, 2007.

[92] A. Frilling, G. C. Sotiropoulos, J. Li, O. Kornasiewicz, and U. Plöckinger, "Multimodal management of neuroendocrine liver metastases," $H P B$, vol. 12, no. 6, pp. 361-379, 2010.

[93] M. de Jong, W. A. P. Breeman, R. Valkema, B. F. Bernard, and E. P. Krenning, "Combination radionuclide therapy using ${ }^{177} \mathrm{Lu}$ and ${ }^{90}$ Y-labeled somatostatin analogs," Journal of Nuclear Medicine, vol. 46, no. 1, 2005.

[94] A. Imhof, P. Brunner, N. Marincek et al., "Response, survival, and long-term toxicity after therapy with the radiolabeled somatostatin analogue $\left[{ }^{90} \mathrm{Y}\right.$-DOTA]-TOC in metastasized neuroendocrine cancers," Journal of Clinical Oncology, vol. 29, no. 17, pp. 2416-2423, 2011.

[95] L. Villard, A. Romer, N. Marincek et al., "Cohort study of somatostatin-based radiopeptide therapy with $\left[{ }^{90} \mathrm{Y}-\mathrm{DOTA}\right]-$ TOC versus $\left[{ }^{90} \mathrm{Y}\right.$-DOTA $]-$ TOC plus $\left[{ }^{177} \mathrm{Lu}\right.$-DOTA $]-$ TOC in neuroendocrine cancers," Journal of Clinical Oncology, vol. 30, no. 10, pp. 1100-1106, 2012.

[96] R. Cescato, S. Schulz, B. Waser et al., "Internalization of $s^{2}{ }_{2}$, sst $_{3}$, and sst $_{5}$ receptors: effects of somatostatin agonists and antagonists," Journal of Nuclear Medicine, vol. 47, no. 3, pp. 502511, 2006.

[97] M. Ginj, H. Zhang, B. Waser et al., "Radiolabeled somatostatin receptor antagonists are preferable to agonists for in vivo peptide receptor targeting of tumors," Proceedings of the National Academy of Sciences of the United States of America, vol. 103, no. 44, pp. 16436-16441, 2006. 
[98] X. Wang, M. Fani, S. Schulz et al., "Comprehensive evaluation of a somatostatin-based radiolabelled antagonist for diagnostic imaging and radionuclide therapy," European Journal of Nuclear Medicine and Molecular Imaging, vol. 39, no. 12, pp. 1876-1885, 2012.

[99] M. Fani, L. del Pozzo, K. Abiraj et al., "PET of somatostatin receptor-positive tumors using ${ }^{64} \mathrm{Cu}$ - and ${ }^{68} \mathrm{Ga}$-somatostatin antagonists: the chelate makes the difference," Journal of Nuclear Medicine, vol. 52, no. 7, pp. 1110-1118, 2011.

[100] D. Wild, M. Fani, M. Behe et al., "First clinical evidence that imaging with somatostatin receptor antagonists is feasible," Journal of Nuclear Medicine, vol. 52, no. 9, pp. 1412-1417, 2011.

[101] M. Schmidt, K. Scheidhauer, C. Luyken et al., "Somatostatin receptor imaging in intracranial tumours," European Journal of Nuclear Medicine, vol. 25, no. 7, pp. 675-686, 1998.

[102] G. Pepe, R. Moncayo, E. Bombardieri et al., "Somatostatin receptor SPECT," European Journal of Nuclear Medicine and Molecular Imaging, vol. 39, Supplement 1, pp. S41-S51, 2012.

[103] W. W. de Herder, D. J. Kwekkeboom, R. A. Feelders et al., "Somatostatin receptor imaging for neuroendocrine tumors," Pituitary, vol. 9, no. 3, pp. 243-248, 2006.

[104] U. Goglia, D. Ferone, M. Sidoti et al., "Treatment of a pituitary metastasis from a neuroendocrine tumour: case report and literature review," Pituitary, vol. 11, no. 1, pp. 93-102, 2008.

[105] S. Baldari, F. Ferrau, C. Alafaci et al., "First demonstration of the effectiveness of peptide receptor radionuclide therapy (PRRT) with ${ }^{111}$ In-DTPA-octreotide in a giant PRL-secreting pituitary adenoma resistant to conventional treatment," Pituitary, vol. 15, Supplement 1, pp. 57-60, 2012.

[106] V. Ambrosini, M. Fani, S. Fanti et al., "Radiopeptide imaging and therapy in Europe," Journal of Nuclear Medicine, vol. 52, Supplement 2, pp. 42S-55S, 2011.

[107] M. M. Graham and Y. Menda, "Radiopeptide imaging and therapy in the United States," Journal of Nuclear Medicine, vol. 52, Supplement 2, pp. 56S-63S, 2011.

[108] L. J. Hofland, "Responsiveness to somatostatin analog treatment and potentials of novel somatostatin analog," Journal of endocrinological investigation, vol. 26, supplement 8, pp. 8-13, 2003.

[109] T. Florio, S. Arena, S. Thellung et al., "The activation of the phosphotyrosine phosphatase $\eta(\mathrm{r}-\mathrm{PTP} \eta)$ is responsible for the somatostatin inhibition of PC CI3 thyroid cell proliferation," Molecular Endocrinology, vol. 15, no. 10, pp. 1838-1852, 2001.

[110] M. Theodoropoulou, J. Zhang, S. Laupheimer et al., "Octreotide, a somatostatin analogue, mediates its antiproliferative action in pituitary tumor cells by altering phosphatidylinositol 3-kinase signaling and inducing Zacl expression," Cancer Research, vol. 66, no. 3, pp. 1576-1582, 2006.

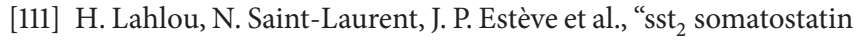
receptor inhibits cell proliferation through Ras-, Rap1-, and B-Raf-dependent ERK2 activation," The Journal of Biological Chemistry, vol. 278, no. 41, pp. 39356-39371, 2003.

[112] P. Pagès, N. Benali, N. Saint-Laurent et al., "sst ${ }_{2}$ somatostatin receptor mediates cell cycle arrest and induction of p27(Kip1). Evidence for the role of SHP-1," The Journal of Biological Chemistry, vol. 274, no. 21, pp. 15186-15193, 1999.

[113] K. Sharma, Y. C. Patel, and C. B. Srikant, "Subtype-selective induction of wild-type p53 and apoptosis, but not cell cycle arrest, by human somatostatin receptor 3," Molecular Endocrinology, vol. 10, no. 12, pp. 1688-1696, 1996.

[114] C. B. Srikant and S. H. Shen, "Octapeptide somatostatin analog SMS 201-995 induces translocation of intracellular PTP1C to membranes in MCF-7 human breast adenocarcinoma cells," Endocrinology, vol. 137, no. 8, pp. 3461-3468, 1996.
[115] S. Arena, A. Pattarozzi, A. Corsaro, G. Schettini, and T. Florio, "Somatostatin receptor subtype-dependent regulation of nitric oxide release: involvement of different intracellular pathways," Molecular Endocrinology, vol. 19, no. 1, pp. 255-267, 2005.

[116] V. Cerovac, J. Monteserin-Garcia, H. Rubinfeld et al., "The somatostatin analogue octreotide confers sensitivity to rapamycin treatment on pituitary tumor cells," Cancer Research, vol. 70, no. 2, pp. 666-674, 2010.

[117] P. Cordelier, J. P. Estève, S. Najib et al., "Regulation of neuronal nitric-oxide synthase activity by somatostatin analogs following $\mathrm{SST}_{5}$ somatostatin receptor activation," The Journal of Biological Chemistry, vol. 281, no. 28, pp. 19156-19171, 2006.

[118] K. Thermos, "Novel signals mediating the functions of somatostatin: the emerging role of NO/cGMP," Molecular and Cellular Endocrinology, vol. 286, no. 1-2, pp. 49-57, 2008.

[119] F. Lopez, G. Ferjoux, P. Cordelier et al., "Neuronal nitric oxide synthase: a substrate for SHP-1 involved in sst $_{2}$ somatostatin receptor growth inhibitory signaling," The FASEB Journal, vol. 15, no. 12, pp. 2300-2302, 2001.

[120] N. Benali, P. Cordelier, D. Calise et al., "Inhibition of growth and metastatic progression of pancreatic carcinoma in hamster after somatostatin receptor subtype $2\left(\mathrm{sst}_{2}\right)$ gene expression and administration of cytotoxic somatostatin analog AN-238," Proceedings of the National Academy of Sciences of the United States of America, vol. 97, no. 16, pp. 9180-9185, 2000.

[121] N. Douziech, E. Calvo, Z. Coulombe et al., "Inhibitory and stimulatory effects of somatostatin on two human pancreatic cancer cell lines: a primary role for tyrosine phosphatase SHP-1," Endocrinology, vol. 140, no. 2, pp. 765-777, 1999.

[122] M. Thangaraju, K. Sharma, D. Liu, S. H. Shen, and C. B. Srikant, "Interdependent regulation of intracellular acidification and SHP-1 in apoptosis," Cancer Research, vol. 59, no. 7, pp. 1649$1654,1999$.

[123] P. D. Zapata, R. M. Ropero, A. M. Valencia et al., "Autocrine regulation of human prostate carcinoma cell proliferation by somatostatin through the modulation of the $\mathrm{SH} 2$ domain containing protein tyrosine phosphatase (SHP)-1," The Journal of Clinical Endocrinology and Metabolism, vol. 87, no. 2, pp. 915926, 2002.

[124] M. C. Zatelli, D. Piccin, F. Tagliati, A. Bottoni, A. Luchin, and E. C. D. Uberti, "Src homology-2-containing protein tyrosine phosphatase-1 restrains cell proliferation in human medullary thyroid carcinoma," Endocrinology, vol. 146, no. 6, pp. 26922698, 2005.

[125] F. Lopez, J. P. Estève, L. Buscail et al., "The tyrosine phosphatase SHP-1 associates with the $\mathrm{sst}_{2}$ somatostatin receptor and is an essential component of $\mathrm{sst}_{2}$-mediated inhibitory growth signaling," The Journal of Biological Chemistry, vol. 272, no. 39, pp. 24448-24454, 1997.

[126] C. Bousquet, N. Delesque, F. Lopez et al., "sst, somatostatin receptor mediates negative regulation of insulin receptor signaling through the tyrosine phosphatase SHP-1," The Journal of Biological Chemistry, vol. 273, no. 12, pp. 7099-7106, 1998.

[127] M. Hortala, G. Ferjoux, A. Estival et al., "Inhibitory role of the somatostatin receptor $\mathrm{sst}_{2}$ on the intracrine-regulated cell proliferation induced by the 210 -amino acid fibroblast growth factor-2 isoform. Implication of JAK2," The Journal of Biological Chemistry, vol. 278, no. 23, pp. 20574-20581, 2003.

[128] G. Ferjoux, F. Lopez, J. P. Esteve et al., "Critical role of Src and SHP-2 in sst ${ }_{2}$ somatostatin receptor-mediated activation of SHP-1 and inhibition of cell proliferation," Molecular Biology of the Cell, vol. 14, no. 9, pp. 3911-3928, 2003.

[129] T. Florio, "Somatostatin/somatostatin receptor signalling: phosphotyrosine phosphatases," Molecular and Cellular Endocrinology, vol. 286, no. 1-2, pp. 40-48, 2008. 
[130] J. Held-Feindt, F. Forstreuter, T. Pufe, and R. Mentlein, "Influence of the somatostatin receptor sst $_{2}$ on growth factor signal cascades in human glioma cells," Molecular Brain Research, vol. 87, no. 1, pp. 12-21, 2001.

[131] M. G. Cattaneo, J. E. Taylor, M. D. Culler, E. Nisoli, and L. M. Vicentini, "Selective stimulation of somatostatin receptor subtypes: differential effects on Ras/MAP kinase pathway and cell proliferation in human neuroblastoma cells," FEBS Letters, vol. 481, no. 3, pp. 271-276, 2000.

[132] T. Florio, A. Scorziello, S. Thellung et al., "Oncogene transformation of $\mathrm{PC} \mathrm{Cl} 3$ clonal thyroid cell line induces an autonomous pattern of proliferation that correlates with a loss of basal and stimulated phosphotyrosine phosphatase activity," Endocrinology, vol. 138, no. 9, pp. 3756-3763, 1997.

[133] A. Massa, F. Barbieri, C. Aiello et al., "The expression of the phosphotyrosine phosphatase DEP-1/PTP $\eta$ dictates the responsivity of glioma cells to somatostatin inhibition of cell proliferation," The Journal of Biological Chemistry, vol. 279, no. 28, pp. 29004-29012, 2004.

[134] A. Massa, F. Barbieri, C. Aiello et al., "The phosphotyrosine phosphatase $\eta$ mediates somatostatin inhibition of glioma proliferation via the dephosphorylation of ERK1/2," Annals of the New York Academy of Sciences, vol. 1030, pp. 264-274, 2004.

[135] S. Arena, A. Pattarozzi, A. Massa et al., "An intracellular multieffector complex mediates somatostatin receptor 1 activation of phospho-tyrosine phosphatase $\eta$," Molecular Endocrinology, vol. 21, no. 1, pp. 229-246, 2007.

[136] E. Ferrante, C. Pellegrini, S. Bondioni et al., "Octreotide promotes apoptosis in human somatotroph tumor cells by activating somatostatin receptor type 2," Endocrine-Related Cancer, vol. 13, no. 3, pp. 955-962, 2006.

[137] J. Guillermet, N. Saint-Laurent, P. Rochaix et al., "Somatostatin receptor subtype 2 sensitizes human pancreatic cancer cells to death ligand-induced apoptosis," Proceedings of the National Academy of Sciences of the United States of America, vol. 100, no. 1, pp. 155-160, 2003.

[138] J. Guillermet-Guibert, N. Saint-Laurent, L. Davenne et al., "Novel synergistic mechanism for $\mathrm{sst}_{2}$ somatostatin and TNF $\alpha$ receptors to induce apoptosis: crosstalk between NF- $\kappa \mathrm{B}$ and JNK pathways," Cell Death and Differentiation, vol. 14, no. 2, pp. 197-208, 2007.

[139] K. Sharma and C. B. Srikant, "Induction of wild-type p53, Bax, and acidic endonuclease during somatostatin-signaled apoptosis in MCF-7 human breast cancer cells," International Journal of Cancer, vol. 76, no. 2, pp. 259-266, 1998.

[140] R. D. Murray, K. Kim, S. G. Ren, M. Chelly, Y. Umehara, and S. Melmed, "Central and peripheral actions of somatostatin on the growth hormone-IGF-I axis," Journal of Clinical Investigation, vol. 114, no. 3, pp. 349-356, 2004.

[141] P. Dasgupta, "Somatostatin analogues: multiple roles in cellular proliferation, neoplasia, and angiogenesis," Pharmacology and Therapeutics, vol. 102, no. 1, pp. 61-85, 2004.

[142] A. Albini, T. Florio, D. Giunciuglio et al., "Somatostatin controls Kaposi's sarcoma tumor growth through inhibition of angiogenesis," The FASEB Journal, vol. 13, no. 6, pp. 647-655, 1999.

[143] T. Florio, M. Morini, V. Villa et al., "Somatostatin inhibits tumor angiogenesis and growth via somatostatin receptor-3-mediated regulation of endothelial nitric oxide synthase and mitogenactivated protein kinase activities," Endocrinology, vol. 144, no. 4, pp. 1574-1584, 2003.

[144] T. Florio, S. Arena, A. Pattarozzi et al., "Basic fibroblast growth factor activates endothelial nitric-oxide synthase in $\mathrm{CHO}$ K1 cells via the activation of ceramide synthesis," Molecular Pharmacology, vol. 63, no. 2, pp. 297-310, 2003.
[145] N. Mastrodimou, F. Kiagiadaki, M. Hodjarova, E. Karagianni, and $\mathrm{K}$. Thermos, "Somatostatin receptors $\left(\mathrm{sst}_{2}\right)$ regulate cGMP production in rat retina," Regulatory Peptides, vol. 133, no. 1-3, pp. 41-46, 2006.

[146] S. Pyronnet, C. Bousquet, S. Najib, R. Azar, H. Laklai, and C. Susini, "Antitumor effects of somatostatin," Molecular and Cellular Endocrinology, vol. 286, no. 1-2, pp. 230-237, 2008.

[147] A. Saveanu and P. Jaquet, "Somatostatin-dopamine ligands in the treatment of pituitary adenomas," Reviews in Endocrine and Metabolic Disorders, vol. 10, no. 2, pp. 83-90, 2009.

[148] T. Tateno, M. Kato, Y. Tani, K. Oyama, S. Yamada, and Y. Hirata, "Differential expression of somatostatin and dopamine receptor subtype genes in adrenocorticotropin (ACTH)-secreting pituitary tumors and silent corticotroph adenomas," Endocrine Journal, vol. 56, no. 4, pp. 579-584, 2009.

[149] A. Fusco, G. Gunz, P. Jaquet et al., "Somatostatinergic ligands in dopamine-sensitive and -resistant prolactinomas," European Journal of Endocrinology, vol. 158, no. 5, pp. 595-603, 2008.

[150] A. Saveanu, I. Morange-Ramos, G. Gunz, H. Dufour, A. Enjalbert, and P. Jaquet, "A luteinizing hormone-, alpha-subunit- and prolactin-secreting pituitary adenoma responsive to somatostatin analogs: in vivo and in vitro studies," European Journal of Endocrinology, vol. 145, no. 1, pp. 35-41, 2001.

[151] A. Yoshihara, O. Isozaki, N. Hizuka et al., "Expression of type 5 somatostatin receptor in TSH-secreting pituitary adenomas: a possible marker for predicting longterm response to octreotide therapy," Endocrine Journal, vol. 54, no. 1, pp. 133-138, 2007.

[152] M. Durán-Prado, A. Saveanu, R. M. Luque et al., "A potential inhibitory role for the new truncated variant of somatostatin receptor 5 , sst 5 TMD4, in pituitary adenomas poorly responsive to somatostatin analogs," The Journal of Clinical Endocrinology and Metabolism, vol. 95, no. 5, pp. 2497-2502, 2010.

[153] G. F. Taboada, R. M. Luque, L. V. Neto et al., "Quantitative analysis of somatostatin receptor subtypes (1-5) gene expression levels in somatotropinomas and correlation to in vivo hormonal and tumor volume responses to treatment with octreotide LAR," European Journal of Endocrinology, vol. 158, no. 3, pp. 295-303, 2008.

[154] S. Melmed, R. Sternberg, D. Cook et al., "A critical analysis of pituitary tumor shrinkage during primary medical therapy in acromegaly," The Journal of Clinical Endocrinology and Metabolism, vol. 90, no. 7, pp. 4405-4410, 2005.

[155] D. C. Danila, J. N. S. Haidar, X. Zhang, L. Katznelson, M. D. Culler, and A. Klibanski, "Somatostatin receptor-specific analogs: effects on cell proliferation and growth hormone secretion in human somatotroph tumors," The Journal of Clinical Endocrinology and Metabolism, vol. 86, no. 7, pp. 2976-2981, 2001.

[156] E. Resmini, P. Dadati, J. L. Ravetti et al., "Clinical case seminar: rapid pituitary tumor shrinkage with dissociation between antiproliferative and antisecretory effects of a longacting octreotide in an acromegalic patient," The Journal of Clinical Endocrinology and Metabolism, vol. 92, no. 5, pp. 15921599, 2007.

[157] T. Florio, S. Thellung, S. Arena et al., "Somatostatin and its analog lanreotide inhibit the proliferation of dispersed human non-functioning pituitary adenoma cells in vitro," European Journal of Endocrinology, vol. 141, no. 4, pp. 396-408, 1999.

[158] T. Florio, S. Thellung, A. Corsaro et al., "Characterization of the intracellular mechanisms mediating somatostatin and lanreotide inhibition of DNA synthesis and growth hormone release from dispersed human GH-secreting pituitary adenoma cells in vitro," Clinical Endocrinology, vol. 59, no. 1, pp. 115-128, 2003. 
[159] T. Cuny, A. Mohamed, T. Graillon et al., "Somatostatin receptor $\mathrm{sst}_{2}$ gene transfer in human prolactinomas in vitro: impact on sensitivity to dopamine, somatostatin and dopastatin, in the control of prolactin secretion," Molecular and Cellular Endocrinology, vol. 355, no. 1, pp. 106-113, 2012.

[160] C. de Bruin, A. M. Pereira, R. A. Feelders et al., "Coexpression of dopamine and somatostatin receptor subtypes in corticotroph adenomas," The Journal of Clinical Endocrinology and Metabolism, vol. 94, no. 4, pp. 1118-1124, 2009.

[161] R. van der Pas, W. W. de Herder, L. Hofland et al., "New developments in medical therapy of Cushing's syndrome," Endocrine-Related Cancer, vol. 19, no. 6, pp. R205-R223, 2012.

[162] L. J. Hofland, J. van der Hoek, R. Feelders et al., "The multiligand somatostatin analogue SOM230 inhibits ACTH secretion by cultured human corticotroph adenomas via somatostatin receptor type 5," European Journal of Endocrinology, vol. 152, no. 4, pp. 645-654, 2005.

[163] M. Boscaro, W. H. Ludlam, B. Atkinson et al., "Treatment of pituitary-dependent Cushing's disease with the multireceptor ligand somatostatin analog pasireotide (SOM230): a multicenter, phase II trial," The Journal of Clinical Endocrinology and Metabolism, vol. 94, no. 1, pp. 115-122, 2009.

[164] V. A. S. H. Dalm, L. J. Hofland, and S. W. J. Lamberts, "Future clinical prospects in somatostatin/cortistatin/somatostatin receptor field," Molecular and Cellular Endocrinology, vol. 286, no. $1-2$, pp. $262-277,2008$.

[165] F. Gatto, F. Barbieri, L. Castelletti et al., "In vivo and in vitro response to octreotide LAR in a TSH-secreting adenoma: characterization of somatostatin receptor expression and role of subtype 5," Pituitary, vol. 14, no. 2, pp. 141-147, 2011.

[166] F. Gatto, F. Barbieri, M. Gatti et al., "Balance between somatostatin and D2 receptor expression drives TSH-secreting adenoma response to somatostatin analogues and dopastatins," Clinical Endocrinology, vol. 76, no. 3, pp. 407-414, 2012.

[167] D. O'Toole, A. Saveanu, A. Couvelard et al., "The analysis of quantitative expression of somatostatin and dopamine receptors in gastro-entero-pancreatic tumours opens new therapeutic strategies," European Journal of Endocrinology, vol. 155, no. 6, pp. 849-857, 2006.

[168] K. E. Öberg, J. Reubi, D. J. Kwekkeboom, and E. P. Krenning, "Role of somatostatins in gastroenteropancreatic neuroendocrine tumor development and therapy," Gastroenterology, vol. 139, no. 3, pp. 742.el-753.e1, 2010.

[169] A. Rinke, H. H. Müller, C. Schade-Brittinger et al., "Placebocontrolled, double-blind, prospective, randomized study on the effect of octreotide LAR in the control of tumor growth in patients with metastatic neuroendocrine midgut tumors: a report from the PROMID study group," Journal of Clinical Oncology, vol. 27, no. 28, pp. 4656-4663, 2009.

[170] C. Bousquet, C. Lasfargues, M. Chalabi et al., "Clinical review: current scientific rationale for the use of somatostatin analogs and mTOR inhibitors in neuroendocrine tumor therapy," The Journal of Clinical Endocrinology and Metabolism, vol. 97, no. 3, pp. 727-737, 2012.

[171] G. Mezo and M. Manea, "Receptor-mediated tumor targeting based on peptide hormones," Expert Opinion on Drug Delivery, vol. 7, no. 1, pp. 79-96, 2010.

[172] N. Dizeyi, L. Konrad, A. Bjartell et al., "Localization and mRNA expression of somatostatin receptor subtypes in human prostatic tissue and prostate cancer cell lines," Urologic Oncology, vol. 7, no. 3, pp. 91-98, 2002.

[173] F. Kosari, J. M. A. Munz, C. D. Savci-Heijink et al., "Identification of prognostic biomarkers for prostate cancer," Clinical Cancer Research, vol. 14, no. 6, pp. 1734-1743, 2008.
[174] L. Lattanzio, F. Tonissi, M. Monteverde et al., "Differential molecular mechanism of docetaxel-octreotide combined treatment according to the docetaxel-resistance status in PC3 prostate cancer cells," Anticancer Drugs, vol. 24, no. 2, pp. 120 130, 2012.

[175] C. Lo Nigro, M. Maffi, J. L. Fischel, P. Formento, G. Milano, and M. Merlano, "The combination of docetaxel and the somatostatin analogue lanreotide on androgen-independent docetaxel-resistant prostate cancer: experimental data," $B J U$ International, vol. 102, no. 5, pp. 622-627, 2008.

[176] A. V. Schally, J. B. Engel, G. Emons, N. L. Block, and J. Pinski, "Use of analogs of peptide hormones conjugated to cytotoxic radicals for chemotherapy targeted to receptors on tumors," Current Drug Delivery, vol. 8, no. 1, pp. 11-25, 2011.

[177] T. W. Friedlander, V. K. Weinberg, E. J. Small et al., "Effect of the somatostatin analog octreotide acetate on circulating insulinlike growth factor-1 and related peptides in patients with nonmetastatic castration-resistant prostate cancer: results of a phase II study," Urologic Oncology, vol. 30, no. 4, pp. 408-414, 2012.

[178] M. Koutsilieris, C. S. Mitsiades, J. Bogdanos et al., "Combination of somatostatin analog, dexamethasone, and standard androgen ablation therapy in stage D3 prostate cancer patients with bone metastases," Clinical Cancer Research, vol. 10, no. 13, pp. 43984405, 2004.

[179] C. S. Mitsiades, J. Bogdanos, D. Karamanolakis, C. Milathianakis, T. Dimopoulos, and M. Koutsilieris, "Randomized controlled clinical trial of a combination of somatostatin analog and dexamethasone plus zoledronate versus zoledronate in patients with androgen ablation-refractory prostate cancer," Anticancer Research, vol. 26, no. 5B, pp. 3693-3700, 2006.

[180] U. Kumar, S. I. Grigorakis, H. L. Watt et al., "Somatostatin receptors in primary human breast cancer: quantitative analysis of mRNA for subtypes $1-5$ and correlation with receptor protein expression and tumor pathology," Breast Cancer Research and Treatment, vol. 92, no. 2, pp. 175-186, 2005.

[181] M. C. Pagliacci, R. Tognellini, F. Grignani, and I. Nicoletti, "Inhibition of human breast cancer cell (MCF-7) growth in vitro by the somatostatin analog SMS 201-995: effects on cell cycle parameters and apoptotic cell death," Endocrinology, vol. 129, no. 5, pp. 2555-2562, 1991.

[182] G. Prevost, E. Foehrle, F. Thomas et al., "Growth of human breast cancer cell lines is inhibited by the somatostatin analog BIM23014," Endocrinology, vol. 129, no. 1, pp. 323-329, 1991.

[183] G. Weckbecker, R. Liu, L. Tolcsvai, and C. Bruns, "Antiproliferative effects of the somatostatin analogue octreotide (SMS 201995) on ZR-75-1 human breast cancer cells in vivo and in vitro," Cancer Research, vol. 52, no. 18, pp. 4973-4978, 1992.

[184] M. Duran-Prado, M. D. Gahete, M. Hergueta-Redondo et al., "The new truncated somatostatin receptor variant sst ${ }_{5}$ TMD4 is associated to poor prognosis in breast cancer and increases malignancy in MCF-7 cells," Oncogene, vol. 31, no. 16, pp. 20492061, 2012.

[185] R. Shi, H. Yu, J. McLarty, and J. Glass, "IGF-I and breast cancer: a meta-analysis," International Journal of Cancer, vol. 111, no. 3, pp. 418-423, 2004.

[186] D. L. Kleinberg, T. L. Wood, P. A. Furth, and A. V. Lee, "Growth hormone and insulin-like growth factor-I in the transition from normal mammary development to preneoplastic mammary lesions," Endocrine Reviews, vol. 30, no. 1, pp. 51-74, 2009.

[187] W. Ruan, F. Fahlbusch, D. R. Clemmons et al., "SOM230 inhibits insulin-like growth factor-I action in mammary gland development by pituitary independent mechanism: mediated through somatostatin subtype receptor 3?” Molecular Endocrinology, vol. 20, no. 2, pp. 426-436, 2006. 
[188] D. L. Kleinberg, P. Ameri, and B. Singh, "Pasireotide, an IGFI action inhibitor, prevents growth hormone and estradiolinduced mammary hyperplasia," Pituitary, vol. 14, no. 1, pp. 4452, 2011.

[189] L. Canobbio, D. Cannata, L. Miglietta, and F. Boccardo, "Somatuline (BIM 23014) and tamoxifen treatment of postmenopausal breast cancer patients: clinical activity and effect on insulin-like growth factor-I (IGF-I) levels," Anticancer Research, vol. 15, no. 6B, pp. 2687-2690, 1995.

[190] J. N. Ingle, V. J. Suman, C. G. Kardinal et al., "A randomized trial of tamoxifen alone or combined with octreotide in the treatment of women with metastatic breast carcinoma," Cancer, vol. 85, no. 6, pp. 1284-1292, 1999.

[191] J. T. Dolan, D. M. Miltenburg, T. S. Granchi, C. C. Miller, and F. C. Brunicardi, "Treatment of metastatic breast cancer with somatostatin analogues-a meta-analysis," Annals of Surgical Oncology, vol. 8, no. 3, pp. 227-233, 2001.

[192] E. Bajetta, G. Procopio, L. Ferrari et al., "A randomized, multicenter prospective trial assessing long-acting release octreotide pamoate plus tamoxifen as a first line therapy for advanced breast carcinoma," Cancer, vol. 94, no. 2, pp. 299-304, 2002.

[193] S. I. Helle, W. Mietlowski, J. P. Guastalla et al., "Effects of tamoxifen and octreotide LAR on the IGF-system compared with tamoxifen monotherapy," European Journal of Cancer, vol. 41, no. 5, pp. 694-701, 2005.

[194] H. Sommer, B. Pröhl-Steimer, E. Bajetta, U. Haus, W. Janni, and A. Kay, "A randomized, double-blind, placebo-controlled, phase 3 trial comparing SMS 201-995 pa LAR plus tamoxifen versus tamoxifen plus placebo in women with locally recurrent or metastatic breast cancer," Zentralblatt fur Gynakologie, vol. 123, no. 10, pp. 557-561, 2001.

[195] K. I. Pritchard, L. E. Shepherd, J. A. Chapman et al., "Randomized trial of tamoxifen versus combined tamoxifen and octreotide LAR therapy in the adjuvant treatment of early-stage breast cancer in postmenopausal women: NCIC CTG MA. 14," Journal of Clinical Oncology, vol. 29, no. 29, pp. 3869-3876, 2011.

[196] V. Vuaroqueaux, A. Dutour, N. Bourhim et al., "Increased expression of the mRNA encoding the somatostatin receptor subtype five in human colorectal adenocarcinoma," Journal of Molecular Endocrinology, vol. 24, no. 3, pp. 397-408, 2000.

[197] C. Z. Qiu, S. Z. Zhu, Y. Y. Wu, C. Wang, Z. X. Huang, and J. L. Qiu, "Relationship between somatostatin receptor subtype expression and clinicopathology, Ki-67, Bcl-2 and p53 in colorectal cancer," World Journal of Gastroenterology, vol. 12, no. 13, pp. 2011-2015, 2006.

[198] M. Bläker, M. Schmitz, A. Gocht et al., "Differential expression of somatostatin receptor subtypes in hepatocellular carcinomas," Journal of Hepatology, vol. 41, no. 1, pp. 112-118, 2004.

[199] K. Szepeshazi, A. V. Schally, A. Nagy, B. W. Wagner, A. M. Bajo, and G. Halmos, "Preclinical evaluation of therapeutic effects of targeted cytotoxic analogs of somatostatin and bombesin on human gastric carcinomas," Cancer, vol. 98, no. 7, pp. 1401-1410, 2003.

[200] G. Palmieri, L. Montella, C. Aiello et al., "Somatostatin analogues, a series of tissue transglutaminase inducers, as a new tool for therapy of mesenchimal tumors of the gastrointestinal tract," Amino Acids, vol. 32, no. 3, pp. 395-400, 2007.

[201] T. Florio, L. Montella, A. Corsaro et al., "In vitro and in vivo expression of somatostatin receptors in intermediate and malignant soft tissue tumors," Anticancer Research, vol. 23, no. 3B, pp. 2465-2471, 2003.

[202] R. Colucci, C. Blandizzi, N. Ghisu, T. Florio, and M. Del Tacca, "Somatostatin inhibits colon cancer cell growth through cyclooxygenase-2 downregulation," British Journal of Pharmacology, vol. 155, no. 2, pp. 198-209, 2008.
[203] S. Cascinu, E. del Ferro, and G. Catalano, "A randomised trial of octreotide vs best supportive care only in advanced gastrointestinal cancer patients refractory to chemotherapy," British Journal of Cancer, vol. 71, no. 1, pp. 97-101, 1995.

[204] R. M. Goldberg, C. G. Moertel, H. S. Wieand et al., "A phase III evaluation of a somatostatin analogue (octreotide) in the treatment of patients with asymptomatic advanced colon carcinoma. North Central Cancer Treatment Group and the Mayo Clinic," Cancer, vol. 76, no. 6, pp. 961-966, 1995.

[205] Y. P. Hua, X. Y. Yin, B. G. Peng et al., "Mechanisms and influence of octreotide-induced regulation of somatostatin receptor 2 on hepatocellular carcinoma," Chemotherapy, vol. 55, no. 5, pp. 312-320, 2009.

[206] Y. Xie, S. Chen, C. H. Wang, and C. W. Tang, "Induction of necrosis in the hepatocellular carcinoma HepG2 xenografts treated with SOM230," Zhonghua Gan Zang Bing Za Zhi, vol. 17, no. 10, pp. 759-764, 2009.

[207] S. D. Prete, L. Montella, M. Caraglia et al., "Sorafenib plus octreotide is an effective and safe treatment in advanced hepatocellular carcinoma: multicenter phase II So.LAR. study," Cancer Chemotherapy and Pharmacology, vol. 66, no. 5, pp. 837$844,2010$.

[208] J. C. Barbare, O. Bouché, F. Bonnetain et al., "Treatment of advanced hepatocellular carcinoma with long-acting octreotide: a phase III multicentre, randomised, double blind placebo-controlled study," European Journal of Cancer, vol. 45, no. 10, pp. 1788-1797, 2009.

[209] K. Jackson, M. Soutto, D. Peng et al., "Epigenetic silencing of somatostatin in gastric cancer," Digestive Diseases and Sciences, vol. 56, no. 1, pp. 125-130, 2011.

[210] S. Gao, B. P. Yu, Y. Li, W. G. Dong, and H. S. Luo, "Antiproliferative effect of octreotide on gastric cancer cells mediated by inhibition of Akt/PKB and telomerase," World Journal of Gastroenterology, vol. 9, no. 10, pp. 2362-2365, 2003.

[211] C. Tang, C. Liu, X. Zhou, and C. Wang, "Enhanced inhibitive effects of combination of rofecoxib and octreotide on the growth of human gastric cancer," International Journal of Cancer, vol. 112, no. 3, pp. 470-474, 2004.

[212] M. T. Huang, Z. X. Chen, B. Wei et al., "Preoperative growth inhibition of human gastric adenocarcinoma treated with a combination of celecoxib and octreotide," Acta Pharmacologica Sinica, vol. 28, no. 11, pp. 1842-1850, 2007.

[213] B. Zhao, P. Yang, J. Yang et al., "A randomized trial of somatostatin to regulate the VEGFs/VEGFRs in patients with gastric cancer," Hepatogastroenterology, vol. 58, no. 109, pp. 1425-1430, 2011.

[214] J. Held-Feindt, B. Krisch, F. Forstreuter, and R. Mentlein, "Somatostatin receptors in gliomas," Journal of Physiology Paris, vol. 94, no. 3-4, pp. 251-258, 2000.

[215] K. Lamszus, W. Meyerhof, and M. Westphal, "Somatostatin and somatostatin receptors in the diagnosis and treatment of gliomas," Journal of Neuro-Oncology, vol. 35, no. 3, pp. 353-364, 1997.

[216] M. G. Cattaneo, D. Gentilini, and L. M. Vicentini, "Deregulated human glioma cell motility: inhibitory effect of somatostatin," Molecular and Cellular Endocrinology, vol. 256, no. 1-2, pp. 3439, 2006.

[217] B. Grobben, P. P. de Deyn, and H. Slegers, "Rat C6 glioma as experimental model system for the study of glioblastoma growth and invasion," Cell and Tissue Research, vol. 310, no. 3, pp. 257-270, 2002.

[218] F. Barbieri and T. Florio, "Characterization of the differential efficiacy of somatostatin receptor agonists in the inhibition of the growth of experimental gliomas and identification of 
the intracellular mechanisms involved," European Journal of Clinical and Medical Oncology, vol. 3, no. 3, pp. 46-53, 2011.

[219] J. C. Reubi, R. Maurer, and J. G. M. Klijn, "High incidence of somatostatin receptors in human meningiomas: biochemical characterization," The Journal of Clinical Endocrinology and Metabolism, vol. 63, no. 2, pp. 433-438, 1986.

[220] S. Arena, F. Barbieri, S. Thellung et al., "Expression of somatostatin receptor mRNA in human meningiomas and their implication in in vitro antiproliferative activity," Journal of NeuroOncology, vol. 66, no. 1-2, pp. 155-166, 2004.

[221] M. C. Chamberlain, "The role of chemotherapy and targeted therapy in the treatment of intracranial meningioma," Current Opinion in Oncology, vol. 24, no. 6, pp. 666-671, 2012.

[222] M. C. Chamberlain, M. J. Glantz, and C. E. Fadul, "Recurrent meningioma: salvage therapy with long-acting somatostatin analogue," Neurology, vol. 69, no. 10, pp. 969-973, 2007. 

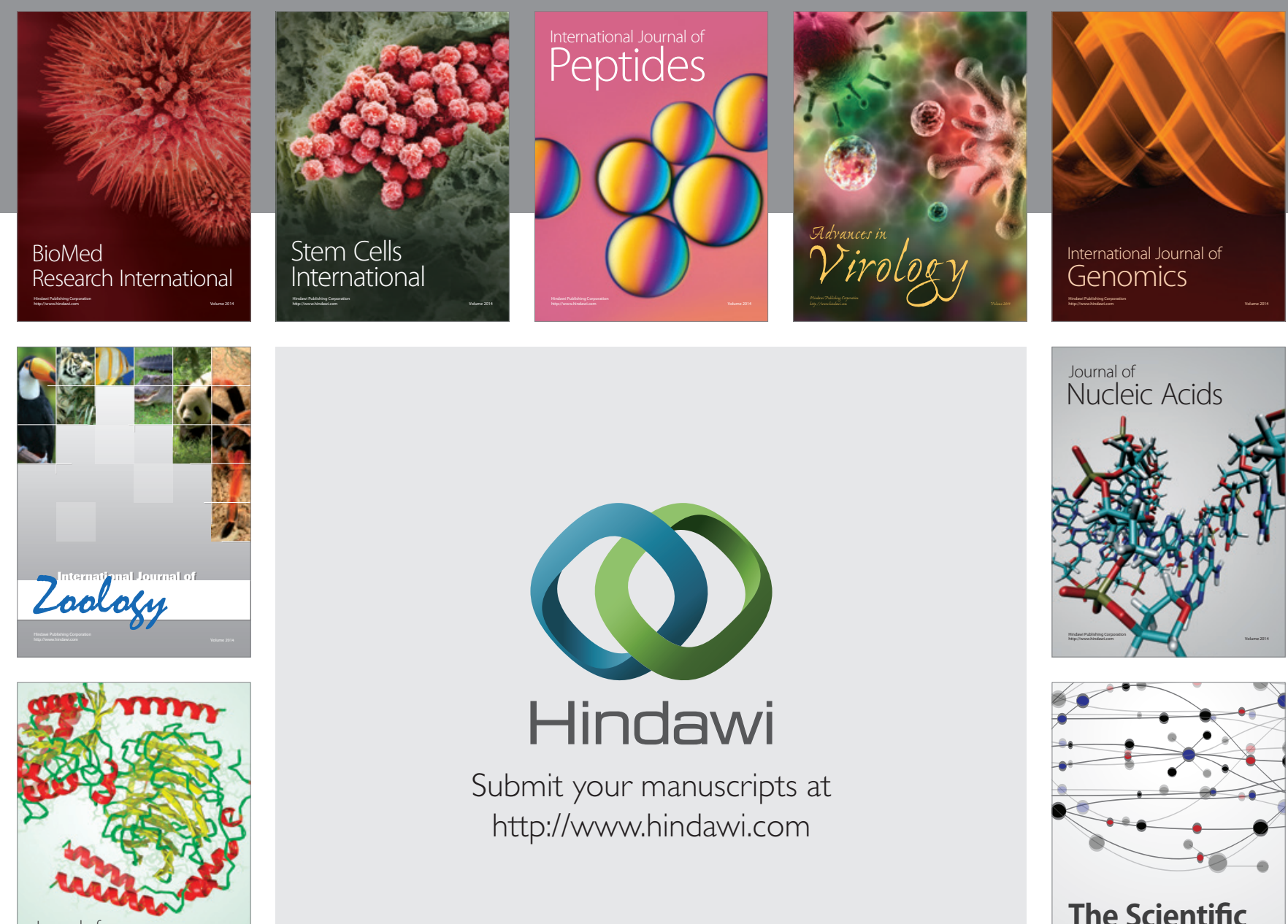

Submit your manuscripts at

http://www.hindawi.com

Journal of
Signal Transduction
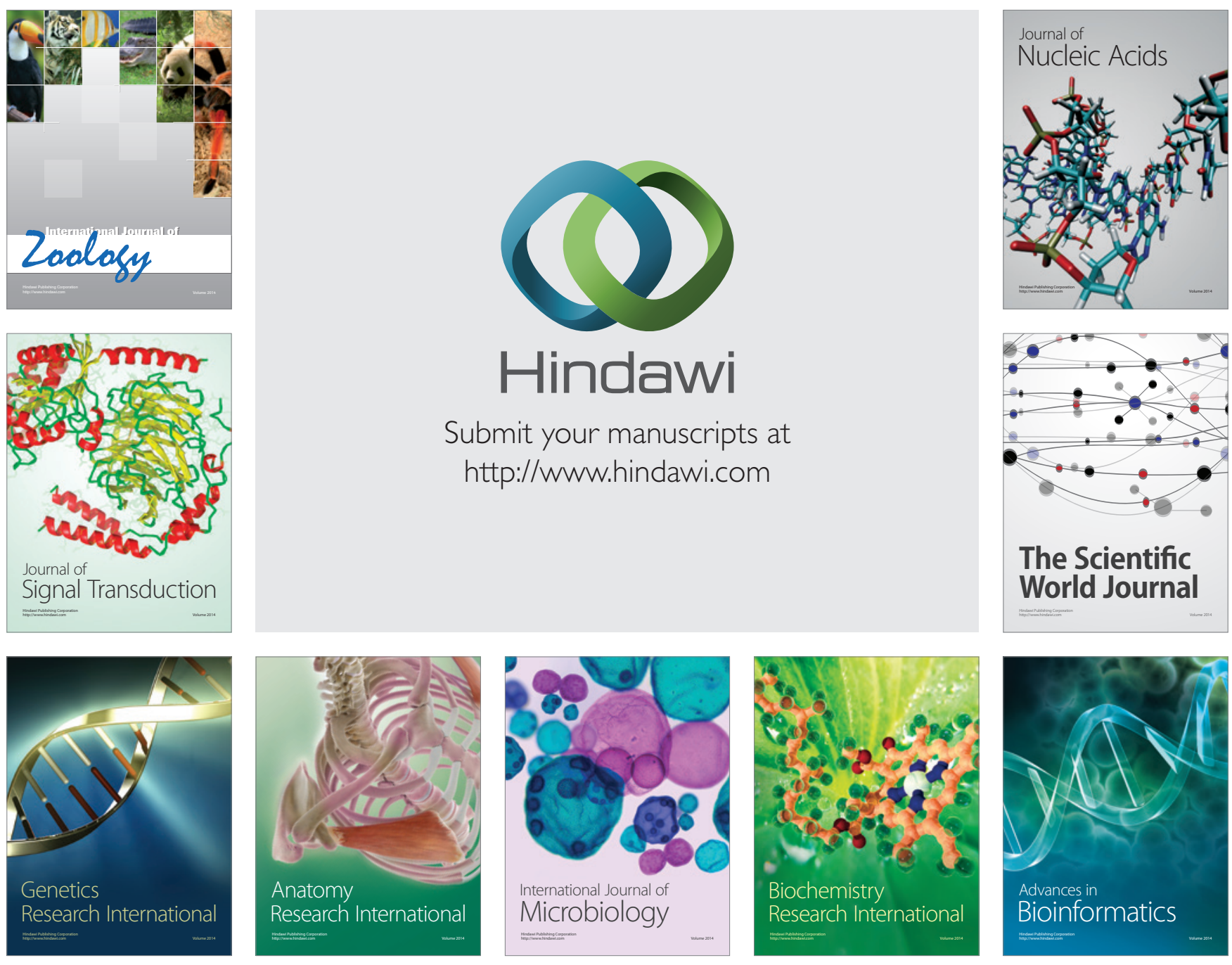

The Scientific World Journal
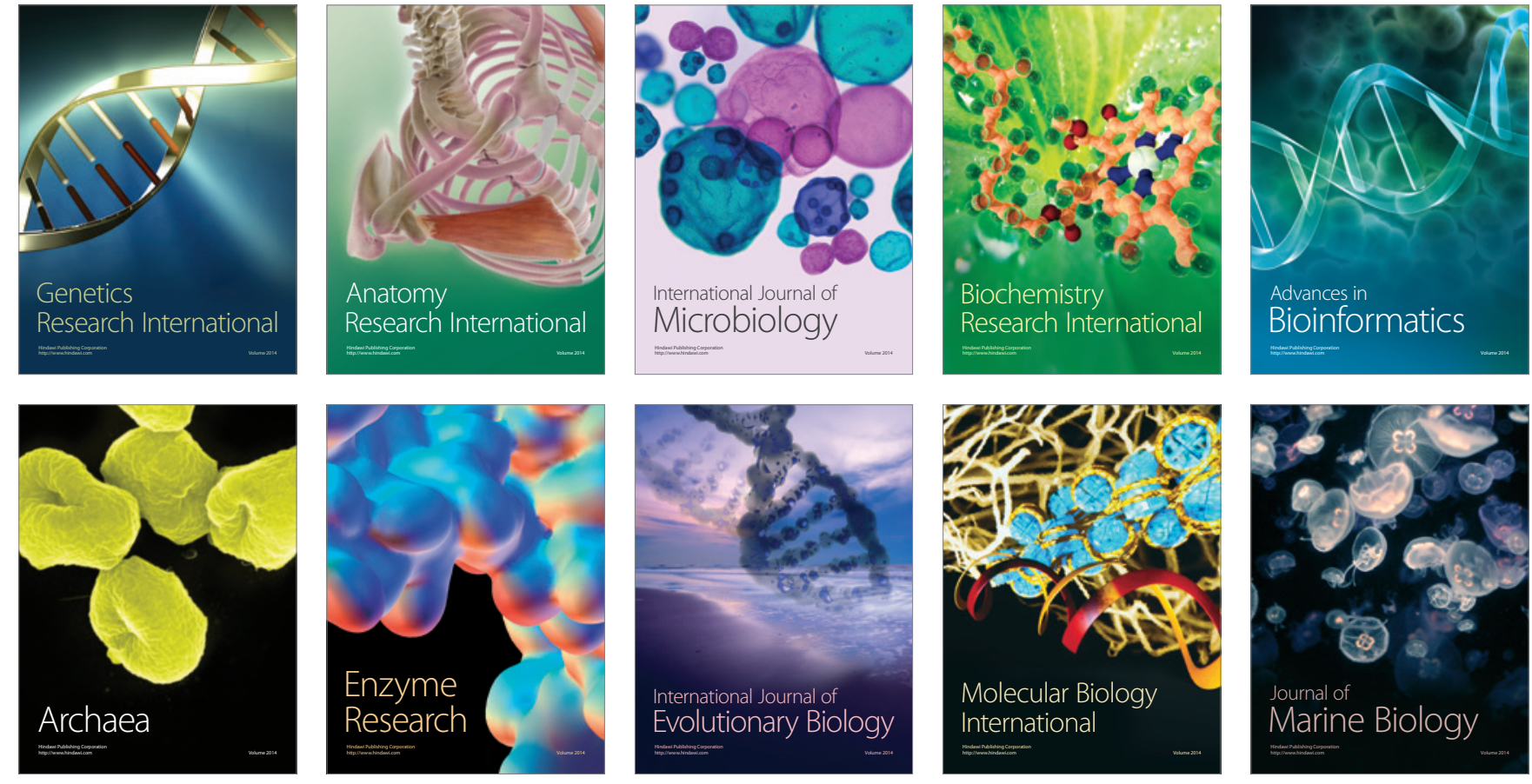